\title{
Preparation and Characterization of Vanadium Oxide Species Supported on Mesoporous Silica for the Hydroxylation of Benzene
}

\author{
Chia-Hung Lee, ${ }^{\dagger}$ Tien-Sung Lin, ${ }^{*, *}$ and Chung-Yuan Mou*,† \\ Department of Chemistry, National Taiwan University, Taipei, Taiwan 106, and Department of Chemistry, \\ Washington University, St. Louis, Missouri 63130
}

Received: September 26, 2006; In Final Form: January 4, 2007

\begin{abstract}
The homogeneous liquid-phase direct catalytic oxidation of benzene to phenol was performed at $60{ }^{\circ} \mathrm{C}$ in acetonitrile solvent using various catalysts of $\mathrm{VO}_{x}$ supported on aluminum-substituted mesoporous silica (AlMPS) and hydrogen peroxide as the oxidant. We employed the molecular designed dispersion method to prepare the $\mathrm{VO}_{x}$ catalyst supported on Al-MPS. The deposit of monolayer $\mathrm{VO}(\mathrm{acac})_{2}$ complexes (acac: acetylacetonate) could be achieved by hydrogen bonding or a ligand-exchange mechanism and subsequently decomposition of organic acac ligands in an oxygen atmosphere at elevated temperature, yielding the six coordination of $\mathrm{V}^{\mathrm{V}}$ center. The octahedral vanadium oxide samples possess much mobile ligands (i.e., $\mathrm{H}_{2} \mathrm{O}$ or solvent) around the catalytic center that could be easily substituted by hydrogen peroxide and yielded the active peroxo intermediate for the hydroxylation of benzene. From the studies of powder X-ray diffraction, $\mathrm{N}_{2}$ adsorption and desorption isotherms, diffuse reflectance $\mathrm{UV}-\mathrm{vis}$, and electron paramagnetic resonance, we show that highly dispersed isolated vanadium oxide catalyst centers could be formed. For comparison, we also prepared the tetrahedral vanadium oxide catalyst by the coordination of $\mathrm{V}^{\mathrm{V}}$ center with mono-, di-, and triamine-modified $\mathrm{SiO}_{2}$. The tetrahedral coordination of vanadium oxide catalysts lack mobile ligands with good leaving groups in the catalytic medium and yield a lower activity toward the hydroxylation of benzene.
\end{abstract}

\section{Introduction}

Phenol is an important industrial feedstock that serves as a precursor for phenol resins, fibers, dyestuffs, and medicine. ${ }^{1}$ Industrially, phenol has been produced in multiple steps from the Hock process or the toluene oxidation. In the former process, acetone is produced as a byproduct in equimolar amount and in the latter case a lower yield is observed. ${ }^{2}$ Many attempts to produce phenol in a one-step process by the direct insertion of an oxygen atom into the $\mathrm{C}-\mathrm{H}$ bond of benzene, and the direct hydroxylation of benzene to phenol with high efficiency and high selectivity have been reported ${ }^{3}$ and thus has attracted much attention. Recently, the reaction has been extensively studied in both liquid and gas phase using a variety of catalysts. In the liquid-phase reaction, the use of hydrogen peroxide as an oxidant in different catalysts system including Ti/MCM-41, TS-1, V-, $\mathrm{Mg}-, \mathrm{Fe}-, \mathrm{Co}-$, and $\mathrm{Cu}$-containing catalysts have been reported. ${ }^{4}$ Besides, the hydroxylation of benzene in the gas phase have been carried out in different catalysts in the presence of nitrous oxide, molecular oxygen, or oxygen-reducing agents. ${ }^{5}$

Furthermore, total oxidation of benzene by using surface polymeric vanadium species and/or the bulk crystalline $\mathrm{V}_{2} \mathrm{O}_{5}$ have been reported previously. Vassileva et al. performed the total oxidation on $\mathrm{V}_{2} \mathrm{O}_{5} / \mathrm{Al}_{2} \mathrm{O}_{3}$ catalyst, ${ }^{6}$ and Noronha et al. showed that the $\mathrm{Pd} / \mathrm{V}_{2} \mathrm{O}_{5} / \mathrm{Al}_{2} \mathrm{O}_{3}$ catalysts are more active than $\mathrm{V}_{2} \mathrm{O}_{5} / \mathrm{Al}_{2} \mathrm{O}_{3}$ and $\mathrm{Pd} / \mathrm{Al}_{2} \mathrm{O}_{3}$ systems. ${ }^{7}$ But Jahnisch et al. showed that consecutive products such as benzoquinone and tar are formed on closely neighboring vanadium sites. $^{8}$ Thus, we speculate that site isolation of vanadium active species is an

* To whom correspondence should be addressed. E-mail: lin@wustl.edu (T.-S.L.); cymou@ntu.edu.tw (C.-Y.M.).

National Taiwan University.

$\doteqdot$ Washington University. important factor for avoiding benzene overoxidation. In this study, we apply the molecular-designed dispersion (MDD) as an effective method for preparing site-isolation of active vanadium species on aluminum substituted mesoporous silica (Al-MPS) with high loading to achieve partial oxidation of benzene.

The catalytic activities of $\mathrm{VO}_{x}$ supported on metal oxides depend on the degree of dispersion. The ability of vanadium to activate the $\mathrm{C}-\mathrm{H}$ bond decreases with increasing $\mathrm{VO}_{x}$ density, whereby the number of $\mathrm{V}-\mathrm{O}-\mathrm{M}$ (support metal atom) bonds per $\mathrm{V}$ is reduced due to the incorporation of vanadium in forming $\mathrm{V}-\mathrm{O}-\mathrm{V}$ bridges. ${ }^{9}$ The nature of $\mathrm{V}-\mathrm{O}-\mathrm{M}$ anchoring bonds appears as a determinant factor for the catalytic behavior of catalysts. Thus, highly dispersed $\mathrm{VO}_{x}$ could enhance catalytic activity in the oxidative activation of $\mathrm{C}-\mathrm{H}$ bond. In recent years, mesoporous silicas have been employed as supports to disperse vanadium to take advantage of their high surface area and applied to the hydroxylation of benzene, ${ }^{10}$ the partial oxidation of ethanol, ${ }^{11}$ and the oxidative destruction of mustard gas analogue. $^{12}$

Highly dispersed $\mathrm{VO}_{x}$ on silica can be prepared by the following three methods: isomorphic substitution, ${ }^{13}$ impregnation (encapsulation), ${ }^{14}$ and grafting. ${ }^{15}$ These methods showed some enhancements in the reactivity, selectivity, separation, and catalyst recovery. In the isomorphic substitution, V-MCM-41 for example, isolated vanadium centers are incorporated in the framework of amorphous silica replacing $\mathrm{Si}$ sites. The sample often gives good activity and selectivity in the hydroxylation of benzene per exposed site. However, the amount of isolated vanadium sites is limited and not all $\mathrm{V}$ sites are exposed. Previously, we have demonstrated that amine functionalized mesoporous MCM-41 solids can be used to encapsulate $\mathrm{V}^{\mathrm{IV}}$ ions $\left(\mathrm{VO}^{2+}\right)$ and produce highly active site-isolated octahedral 
vanadium center for the hydroxylation of benzene using hydrogen peroxide as an oxidant. ${ }^{16}$ The $\mathrm{V}^{\mathrm{IV}}$ catalytic centers are first oxidized to $\mathrm{V}^{\mathrm{V}}$, and a reactive hydroxyl radical is generated. Further, the oxidized $\mathrm{V}^{\mathrm{V}}$ centers react with a second molecule of hydrogen peroxide and a reactive peroxo radical is produced as an active intermediate for the hydroxylation of benzene. In that study, we showed that VIV catalysts could control the availability of mobile ligands in the $\mathrm{V}^{\mathrm{IV}}$ center, and yield the active radicals for the hydroxylation of benzene. However, the high activity of immobilized VIV leads to an overoxidation and a low selectivity of targeted phenol. Thus, it would be desirable to find another method to maintain single site $\mathrm{V}^{\mathrm{V}}$ centers and to achieve a better catalytic selectivity.

Previously, Vansant and co-workers have demonstrated that the MDD method is a promising technique to obtain a highly dispersed transition metal oxide on inorganic supports. ${ }^{17}$ In this study, we adapt the MDD method to graft vanadium oxide catalysts on mesoporous aluminosilicate. This technique is based on the reaction of the metal acetylacetonate complex with the surface hydroxyls of silica supports. Subsequently, the adsorbed complexes are decomposed in an oxidative condition after a controlled calcination in air flow, and yield highly dispersed transition-metal oxide catalysts. This method is particularly suitable for site isolation in mesostructural supports where isolation can be maintained even at maximum $\mathrm{V}$ loading.

In this report, we will first present several variants of MDD methods applied to the deposition of $\mathrm{VO}_{x}$ on Al-MPS with different pore sizes. We then examine the coordination environments of the vanadium oxide in Al-MPS and correlated with the catalytic activity by electron paramagnetic resonance (EPR) and UV-vis spectral techniques. For comparison purposes, we also synthesized the tetrahedral coordination of $\mathrm{V}^{\mathrm{V}}$ centers using amine-modified solid supports, so that we could examine the effect of coordination of vanadium centers (octahedral vs tetrahedral) on the catalytic activity. The catalytic studies of the hydroxylation of benzene showed that the presence of mobile ligands (i.e., solvent or $\mathrm{H}_{2} \mathrm{O}$ ) could facilitate the $\mathrm{V}^{\mathrm{V}}$ center to form reactive intermediates and offer good product selectivity.

\section{Experimental Section}

1. Preparation of Catalysts. The preparation methods of the following mesoporous silica (MPS) were described in previous reports: aluminum-substituted MCM-41, MCM-48, and MAS-9 samples. ${ }^{18}$ Sodium Y zeolite was purchased from Sigma Chemical Co. Deposition of $\mathrm{VO}(\mathrm{acac})_{2}$ complex onto the AlMPS surface was carried out by the liquid-phase MDD method. About $0.4 \mathrm{~g}$ of uncalcined or calcined Al-MPS was stirred in $30 \mathrm{~mL}$ of toluene solution containing $0.06 \mathrm{~g}$ of $\mathrm{VO}(\mathrm{acac})_{2}$ complexes for $3 \mathrm{~h}$ at room temperature. The solids were then filtered and washed three times with toluene to remove the excess metal complexes. The filtered samples were dried under vacuum and these final products were denoted as NaY-, MCM41-, MCM-48-, and MAS-9-VO(acac) 2 . Furthermore, the above samples were calcined at $580{ }^{\circ} \mathrm{C}$ for $8 \mathrm{~h}$ in air to remove the organic part, and these samples were denoted as NaY-, MCM41-, MCM-48-, and MAS-9- $\mathrm{VO}_{x}$.

In the following studies, we found that the MCM-41-, MCM48-, and MAS-9- $\mathrm{VO}_{x}$ samples could be prepared efficiently by the following simple procedure: the $\mathrm{VO}(\mathrm{acac})_{2}$ complexes were first dissolved in a toluene solution, then the uncalcined samples (with the surfactant molecule remained in the channels) of MPS were added to the above solution. After stirring for 3 $\mathrm{h}$, the samples were collected by filtration and dried under vacuum. The as-synthesized samples were denoted as UC-
MCM-41-, UC-MCM-48-, and UC-MAS-9-VO(acac) $)_{2}$. The above samples could be further calcined at $580{ }^{\circ} \mathrm{C}$ and the products were mono-dispersion of vanadium oxides which were denoted as UC-MCM-41-, UC-MCM-48-, and UC-MAS-9-VO ${ }_{x}$.

In order to compare the activities of tetrahedral and octahedral $\mathrm{V}^{\mathrm{V}}$ catalytic centers, we modified the surface of silica gel with organic silane containing mono-, di-, and triamine groups. The anchoring of amino silane groups onto the surfaces of silica gel was prepared as follows: $6.0 \mathrm{~g}$ of silica gel was placed in $150 \mathrm{~mL}$ of EtOH and stirred for $30 \mathrm{~min}$. A sample of $13 \mathrm{mmol}$ of aminosilane (3-aminopropyltrimethoxysilane, 3-(2-Aminoethyl)aminopropyl trimethoxysilane, or 3-2-(2-aminoethylamino)ethylaminopropyltrimethoxysilane) was added to the resulting mixture. The above mixture was allowed to react for $8 \mathrm{~h}$ at $80{ }^{\circ} \mathrm{C}$. The solids were washed twice with $\mathrm{EtOH}$. The filtered samples were dried under a vacuum.

The $\mathrm{V}^{\mathrm{V}}$ center could be further grafted onto the surface of amine modified silica gel and aluminum oxide by coordination and impregnation. The samples were prepared as follows: $2 \mathrm{~g}$ of amine-modified silica gel was introduced into $33 \mathrm{~mL}$ of aqueous solution containing $0.3 \mathrm{mmol}$ of $\mathrm{NH}_{4} \mathrm{VO}_{3}$ and then stirred for $1 \mathrm{~h}$. The samples were collected by filtration and washed with $\mathrm{H}_{2} \mathrm{O}$ then dried at $100{ }^{\circ} \mathrm{C}$ to obtain the products that were denoted as $\mathrm{SiO}_{2}-\mathrm{N}_{1}-\mathrm{VO}_{x}, \mathrm{SiO}_{2}-\mathrm{N}_{2}-\mathrm{VO}_{x}$, and $\mathrm{SiO}_{2}-\mathrm{N}_{3}-\mathrm{VO}_{x}$, where $\mathrm{N}_{1}, \mathrm{~N}_{2}$, and $\mathrm{N}_{3}$ represent the number of amine groups per silane moiety. The impregnation of $\mathrm{NH}_{4} \mathrm{VO}_{3}$ onto the surface of aluminum oxide was prepared as follows: $6 \mathrm{~g}$ of $\mathrm{Al}_{2} \mathrm{O}_{3}$ in $30 \mathrm{~mL}$ of $\mathrm{H}_{2} \mathrm{O}$ containing $0.56 \mathrm{mmol}$ of $\mathrm{NH}_{4}-$ $\mathrm{VO}_{3}$ under stirring at room temperature for $3 \mathrm{~h}$. The sample was then dried at $100{ }^{\circ} \mathrm{C}$ for 1 day. The solid sample was further calcined at $500{ }^{\circ} \mathrm{C}$ for $5 \mathrm{~h}$ and denoted as $\mathrm{Al}_{2} \mathrm{O}_{3}-\mathrm{VO}_{x}$.

2. Catalytic Activities. The catalytic activities were evaluated at $60{ }^{\circ} \mathrm{C}$ by the reaction of benzene and hydrogen peroxide using acetonitrile as a solvent. A typical catalytic condition is the following: $0.06 \mathrm{~g}$ of catalyst was first placed in a $25-\mathrm{mL}$ roundbottom flask with a condenser cooled at $5^{\circ} \mathrm{C}$, and then $10 \mathrm{mmol}$ of benzene in $8.2 \mathrm{~mL}$ of acetonitrile solution was added. After stirring for $5 \mathrm{~min}, 10 \mathrm{mmol}$ of $\mathrm{H}_{2} \mathrm{O}_{2}$ ( $35 \%$ in aqueous solution) were added, and the total volume was kept as $10 \mathrm{~mL}$. Aliquots were withdrawn after $3 \mathrm{~h}$; they were diluted 25 times with acetonitrile and analyzed by a Gilson 306 liquid chromatograph using an RP-18 $(4.6 \times 250 \mathrm{~mm})$ column. The mobile phase was an acetonitrile/water mixed solution $\left(\mathrm{CH}_{3} \mathrm{CN}: \mathrm{H}_{2} \mathrm{O}=60\right.$ : 40) with a flow rate of $1.5 \mathrm{~mL} / \mathrm{min}$, and a UV-vis detector set at $260 \mathrm{~nm}$ wavelength. The retention times of benzene, phenol, and 1,4-benzoquinone under above conditions were 4.18, 2.09, and $1.94 \mathrm{~min}$, respectively. For the quantitative assay of benzene, phenol, and 1,4-benzoquinone, the high-performance liquid chromatography (HPLC) chromatogram was calibrated using known quantities of above compounds (from Acros). The turnover number (TON) was determined by the moles of benzene converted per mole of vanadium in the catalyst per hour.

3. Characterization Techniques. Nitrogen and carbon contents of the samples were analyzed with a Perkin-Elmer CHN-2400 instrument. Vanadium contents of the samples were analyzed with a simultaneous inductively coupled plasma atomic emission spectrometry allied analytical system (Jarrel-Ash, Model ICAP 9000). UV-visible spectra were taken on a Hitachi U-3010 spectrophotometer. When dealing with solid samples, an integrating sphere was included to collect the reflected light. A Bruker EMX EPR spectrometer (X-band) was employed to measure the EPR spectra of samples. The powdered sample used for the analysis was introduced in a quartz tubing of $4 \mathrm{~mm}$ 
TABLE 1: Surface Area, Pore Size, and Pore Volume of Al-MPS Samples before and after Encapsulation of VO(acac $)_{2}$ Complexes

\begin{tabular}{|c|c|c|c|}
\hline sample & $\begin{array}{c}\text { surface area } \\
\left(\mathrm{m}^{2} / \mathrm{g}\right)\end{array}$ & $\begin{array}{c}\text { pore size } \\
(\AA)\end{array}$ & $\begin{array}{l}\text { pore volume } \\
\left(\mathrm{cm}^{3} / \mathrm{g}\right)\end{array}$ \\
\hline $\mathrm{NaY}$ & 810 & 7.4 & 0.340 \\
\hline MCM-41 & 1102 & 25.8 & 1.034 \\
\hline MCM-48 & 1012 & 27.0 & 0.892 \\
\hline MAS-9 & 843 & 90.0 & 1.057 \\
\hline $\mathrm{NaY}-\mathrm{VO}(\text { acac })_{2}$ & 694 & N.D. ${ }^{a}$ & 0.322 \\
\hline MCM-41-VO (acac $)_{2}$ & 852 & 21.0 & 0.753 \\
\hline MCM-48-VO (acac $)_{2}$ & 803 & 24.5 & 0.610 \\
\hline MAS-9-VO (acac $)_{2}$ & 579 & 88.0 & 0.823 \\
\hline $\mathrm{NaY}-\mathrm{VO}_{x}$ & 543 & N.D. & 0.252 \\
\hline MCM-41-VO & 839 & 24.0 & 0.843 \\
\hline $\mathrm{MCM}-48-\mathrm{VO}_{x}$ & 896 & 26.5 & 0.747 \\
\hline MAS-9-VO ${ }_{x}$ & 679 & 84.0 & 1.022 \\
\hline UC-MCM-41-VO(acac $)_{2}$ & 182 & N.D. & 0.227 \\
\hline UC-MCM-48-VO(acac $)_{2}$ & 601 & 17.0 & 0.249 \\
\hline UC-MCM-9-VO (acac $)_{2}$ & 276 & 83.0 & 0.515 \\
\hline UC-MCM-41-VO & 893 & 24.5 & 0.914 \\
\hline UC-MCM-48- $\mathrm{VO}_{x}$ & 1040 & 27.0 & 0.959 \\
\hline UC-MAS-9-VO ${ }_{x}$ & 692 & 85.0 & 0.926 \\
\hline
\end{tabular}

${ }^{a}$ N.D. $=$ not determined.

outside diameter. The sample was degassed and sealed under vacuum. The spectrometer was equipped with a variable temperature controller, which allowed us to record spectra at low temperatures, mostly at $80 \mathrm{~K}$. Typical spectrometer settings were microwave frequency $9.53 \mathrm{GHz}$, microwave power 1.98 $\mathrm{mW}$, modulation amplitude $5 \mathrm{G}$, and one scan at $167 \mathrm{~s}$.

\section{Results and Discussion}

1. Adsorption Studies. Table 1 summarizes the surface area, pore size, and pore volume of $\mathrm{VO}(\mathrm{acac})_{2}$ complexes incorporated in the calcined and uncalcined samples of Al-MPS. The NaY, MCM-41, MCM-48, and MAS-9 samples showed a decrease in the surface area $\left(\sim 200-300 \mathrm{~m}^{2} / \mathrm{g}\right)$, pore size (about $3-5 \AA$ ), and pore volume $\left(0.23-0.28 \mathrm{~cm}^{3} / \mathrm{g}\right)$ after $\mathrm{VO}(\mathrm{acac})_{2}$ complexes were loaded. The decrease of these three parameters indicated that the $\mathrm{VO}(\mathrm{acac})_{2}$ complexes were mostly monodispersed in the nanochannels of MPS. The MPS-VO(acac $)_{2}$ samples were further calcined under $580{ }^{\circ} \mathrm{C}$ for $8 \mathrm{~h}$, and the complexes inside the MPS solid supports were converted into $\mathrm{VO}_{x}$ with good dispersion as shown in Table 1, listed as NaY-, MCM-41-, MCM-48-, and MAS-9-VO ${ }_{x}$ samples. The high surface area and the presence of well-ordered pore structure in the calcined samples indicated that the mesoporous silica have structural stability for the immobilized $\mathrm{VO}_{x}$ catalyst.

On the other hand, in the $\mathrm{VO}(\mathrm{acac})_{2}$ complexes encapsulated in the uncalcined samples of MPS, where the nanochannels were occupied by surfactant molecule, we observed low surface area of 182,601 , and $276 \mathrm{~m}^{2} / \mathrm{g}$ for the uncalcined samples of MCM41, MCM-48, and MAS-9, respectively. The observed smaller pore volume indicated that the $\mathrm{VO}(\mathrm{acac})_{2}$ complexes were in the nanochannels of uncalcined MPS containing the surfactant molecule (CTAB or P123). Upon further calcinations, the organic parts of acac ligands and surfactant molecule were removed, and we observed an increase of both the surface area and pore volume in UC-MPS- $\mathrm{VO}_{x}$ samples. From the analyses of $\mathrm{UV}-$ vis and EPR spectra, we further confirm that the monodispersion of $\mathrm{VO}_{x}$ catalyst could be prepared by the one step encapsulation of $\mathrm{VO}(\mathrm{acac})_{2}$ complexes in the uncalcined samples of Al-MPS.

2. Chemical Analysis. Table 2 shows the vanadium content in different supports. We note that the loading of $\mathrm{VO}(\mathrm{acac})_{2}$ complexes is higher in the larger pore size of solid supports.
TABLE 2: Elemental Analysis of Vanadium Content in Solid Supports

\begin{tabular}{|c|c|c|c|}
\hline sample & $\begin{array}{l}\text { mmol of } \\
\text { V/100 g } \\
\text { of sample }\end{array}$ & sample & $\begin{array}{l}\text { mmol of } \\
\mathrm{V} / 100 \mathrm{~g} \\
\text { of sample }\end{array}$ \\
\hline $\mathrm{NaY}-\mathrm{VO}(\mathrm{acac})_{2}$ & 36.51 & & \\
\hline MCM-41-VO(acac $)_{2}$ & 86.77 & UC-MCM-41-VO ${ }_{x}$ & 44.36 \\
\hline $\mathrm{MCM}-48-\mathrm{VO}(\mathrm{acac})_{2}$ & 87.55 & UC-MCM-48-VO & 56.34 \\
\hline MAS-9-VO-(acac) $)_{2}$ & 96.19 & UC-MAS-9-VO ${ }_{x}$ & 15.45 \\
\hline $\mathrm{NaY}-\mathrm{VO}_{x}$ & 43.19 & $\mathrm{Al}_{2} \mathrm{O}_{3}-\mathrm{VO}_{x}$ & 15.51 \\
\hline $\mathrm{MCM}-41-\mathrm{VO}_{x}$ & 89.12 & $\mathrm{SiO}_{2}-\mathrm{N}_{1}-\mathrm{VO}_{x}$ & 54.57 \\
\hline $\mathrm{MCM}-48-\mathrm{VO}_{x}$ & 98.54 & $\mathrm{SiO}_{2}-\mathrm{N}_{2}-\mathrm{VO}_{x}$ & 116.41 \\
\hline MAS-9-VO & 89.91 & $\mathrm{SiO}_{2}-\mathrm{N}_{3}-\mathrm{VO}_{x}$ & 75.18 \\
\hline
\end{tabular}

TABLE 3: Mole Ratios of acac Ligands and Vanadium in Different Supports

\begin{tabular}{lc}
\hline \multicolumn{1}{c}{ sample } & acac/V \\
\hline $\mathrm{NaY}-\mathrm{VO}(\mathrm{acac})_{2}$ & 0.530 \\
$\mathrm{MCM}-41-\mathrm{VO}(\mathrm{acac})_{2}$ & 1.769 \\
$\mathrm{MCM}-48-\mathrm{VO}(\mathrm{acac})_{2}$ & 1.336 \\
MAS-9-VO-(acac $)_{2}$ & 0.821
\end{tabular}

The pore sizes of the MPS solids used in our studies are: 9.0 $\mathrm{nm}$ for MAS-9, $2.7 \mathrm{~nm}$ for MCM-48, $2.6 \mathrm{~nm}$ for MCM-41, and $0.74 \mathrm{~nm}$ for $\mathrm{NaY}$ samples. Thus, MAS-9 has the highest loading, about 96 mmole of vanadium per $100 \mathrm{~g}$ of samples. The vanadium loadings in MCM-41 and MCM-48 samples are about $87 \mathrm{mmol}$ per $100 \mathrm{~g}$ of samples. On the other hand, the pore size of $\mathrm{NaY}$ zeolite (micropore) is too small to accommodate $\mathrm{VO}(\mathrm{acac})_{2}$ complexes. However, in the uncalcined samples of Al-MPS encapsulated with $\mathrm{VO}(\mathrm{acac})_{2}$ complexes, we note that MCM-41 and MCM-48 samples have higher vanadium loading than MAS-9 sample. We attribute the effect to the electrostatic interaction between the MPS surface and $\mathrm{VO}(\mathrm{acac})_{2}$, where a cationic surfactant $(\mathrm{CTAB})$ was used in the preparation of MCM-41 and MCM-48 vs nonionic copolymer (Pluronic P123) used as a template in MAS-9 samples. This is also clearly observed in our EPR studies.

Furthermore, the value of mole ratios of the organic ligands (acac) and the inorganic vanadium in the sample can provide information about the mechanism of immobilization of VO$(\text { acac })_{2}$ complexes in the solid supports either by hydrogen bonding or ligand exchange. If the $\mathrm{VO}(\mathrm{acac})_{2}$ complexes go through the hydrogen bonding to graft on the surface, the mole ratio of acac ligands to vanadium should be very close to 2 (Chart 1 A). If the surfaces of solid supports are occupied by active groups, the acac ligands in the complexes will be replaced by ligand exchange mechanism and the value of mole ratio should be less than $2 .{ }^{17 \mathrm{a}-\mathrm{c}}$ From the mole ratios given in Table 3 , we note that the $\mathrm{VO}(\mathrm{acac})_{2}$ grafted in $\mathrm{NaY}$ zeolite mainly by the ligand exchange mechanism and the two acac ligands in the $\mathrm{VO}(\mathrm{acac})_{2}$ complexes will be replaced almost completely (Chart 1D). However, when $\mathrm{VO}(\text { acac })_{2}$ complexes were grafted in the solid surface of MCM-41, MCM-48, and MAS-9 samples, we observed a value of $\sim 0.8-1.8$. The values indicated that at least one or maybe two acac ligands in the $\mathrm{VO}(\text { acac })_{2}$ complexes were replaced by active hydroxyl groups on the solid surface. Since we observed that the acac/V ratios are always less than 2 which imply no leaching of vanadyl ions into the solution.

3. Powder X-ray Diffraction (XRD). Figure 1 shows the XRD patterns of aluminum substituted MCM-41, MCM-48, and MAS-9 samples before and after the encapsulation of $\mathrm{VO}(\mathrm{acac})_{2}$ complexes. As expected, these $\mathrm{VO}(\mathrm{acac})_{2}$-containing MPS samples will exhibit their characteristic peaks assignable to hexagonal P6mm symmetry for MCM-41 and MAS-9 samples and cubic Ia3d symmetry for MCM-48 samples. The spectra display the hexagonal symmetry with (100), (110), and (200) 
CHART 1: Modes of Coordination in the VO(acac $)_{2}$ Complexes Encapsulated on the Surface of Aluminum Substituted Mesoporous Silica

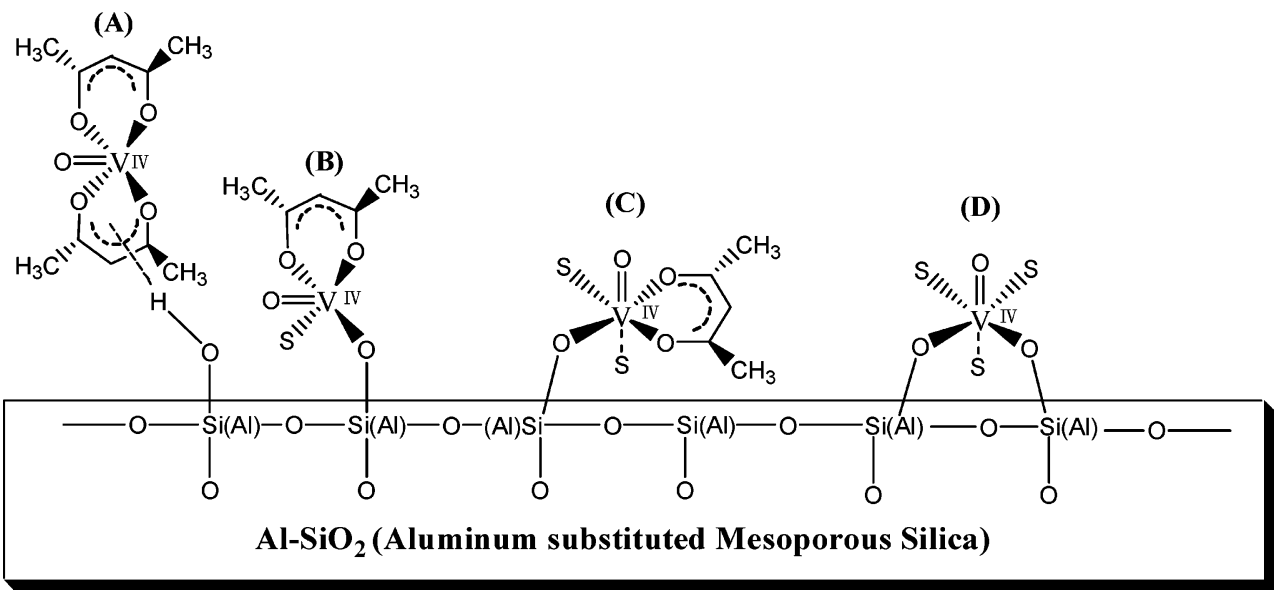

and the cubic symmetry with (211), (220), (420), and (332) diffraction peaks. The XRD diffraction intensity is slightly reduced after the encapsulation of $\mathrm{VO}(\mathrm{acac})_{2}$ complexes in the solid supports. The XRD patterns show that the encapsulation of $\mathrm{VO}(\mathrm{acac})_{2}$ complexes in MPS in toluene solution do not affect the integrity of the well-defined mesostructure of solid supports. The decrease of intensity may arise from the larger contrast in the density between the silica walls and the empty pores relative to that between the silica walls and the pores filled with VO(acac) $)_{2}$ complexes.

4. Diffuse Reflectance UV-Vis Spectra. The nature of coordination of vanadium center in MPS was studied by UVvis spectra. The energy of charge-transfer (CT) bands $\left(\mathrm{O}^{2-}\right.$ to $\mathrm{V}^{5+}$ ) depends on the environment of the vanadium center. A lower coordination number results in a shift of the CT band to higher energy (lower wavelength). The spectra of MPS supported $\mathrm{VO}_{x}$ are shown in Figure 2. Three broad bands at around

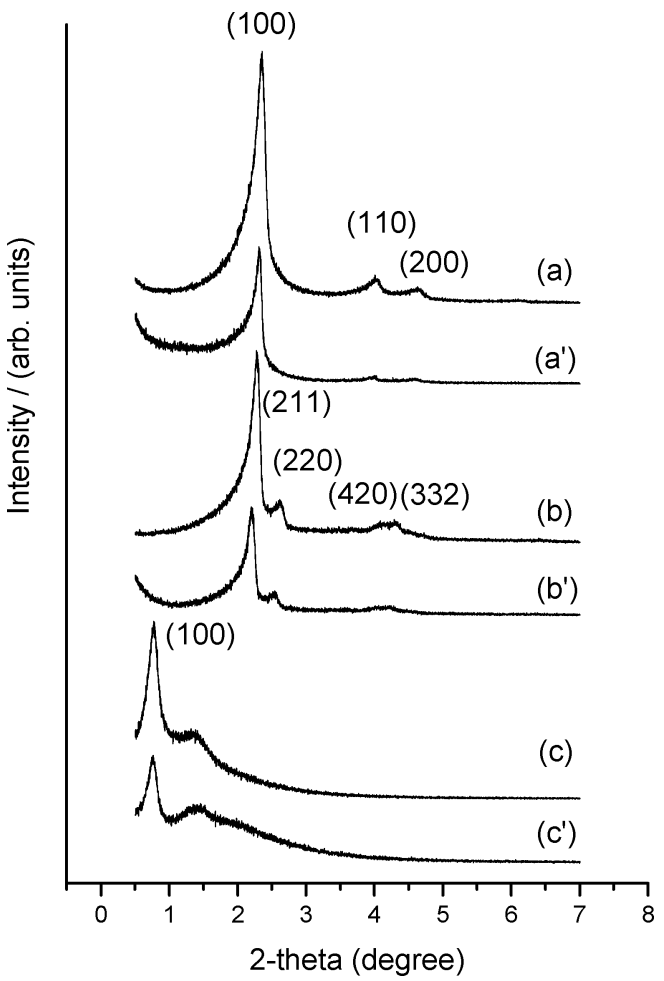

Figure 1. XRD powder spectra of the following samples: (a) MCM41, (b) MCM-48, and (c) MAS-9 samples before (a, b, and c) and after $\left(a^{\prime}, b^{\prime}\right.$, and $\left.c^{\prime}\right)$ encapsulation of $\mathrm{VO}(\mathrm{acac})_{2}$ complexes.
250, 340, and $412 \mathrm{~nm}$, respectively, are assigned to CT bands. Previous studies showed the following: (1) the strong CT band at around $250 \mathrm{~nm}$ was assigned to an isolated tetrahedral $\mathrm{V}^{\mathrm{V}}$, (2) the band at around $340 \mathrm{~nm}$ was attributed to $\mathrm{V}^{\mathrm{V}}$ with $\mathrm{V}=\mathrm{O}$ double and $\mathrm{V}-\mathrm{O}$ single bonds, (3) the band at around $412 \mathrm{~nm}$ to a square pyramidal, and (4) the band at around $458 \mathrm{~nm}$ to a distorted octahedral $\mathrm{V}^{\mathrm{V}} \cdot{ }^{10 \mathrm{~b}, 13 \mathrm{c}, 19}$ Besides, these studies also showed that $\mathrm{H}_{2} \mathrm{O}$ is easily coordinated to $\mathrm{V}^{\mathrm{V}}$ centers; the coordinated samples can undergo a dramatic color change from bright white to dark orange upon standing in ambient air atmosphere. The variation in color is attributed to the change of the coordination number from tetrahedral $\mathrm{V}^{\mathrm{V}}$ complexes to (pseudo) octahedral structure by coordinating with water molecules. ${ }^{17 f}$ The spectra of MPS- $\mathrm{VO}_{x}$ samples before heating are shown as solid line traces, and after heating at $300{ }^{\circ} \mathrm{C}$ for $2 \mathrm{~h}$ are shown as dotted line traces. After heating, we observed the intensities of bands at 412 and $458 \mathrm{~nm}$ of MCM-41, MCM48, and MAS-9-VO $\mathrm{VO}_{x}$ samples (spectra $\mathrm{b}^{\prime}-\mathrm{d}^{\prime}$ of Figure 2) decreased and those of bands at 250 and $340 \mathrm{~nm}$ increased. These spectral changes are attributed to the release of water from the coordination sphere of octahedral $\mathrm{V}^{\mathrm{V}}$ and the transformation of octahedral $\mathrm{V}^{\mathrm{V}}$ centers to tetrahedral $\mathrm{V}^{\mathrm{V}}$, which could contribute additional intensity to the bands at 250 and $340 \mathrm{~nm}$. Because the process is reversible, the results may infer the presence of mobile coordination between the $\mathrm{H}_{2} \mathrm{O}$ with $\mathrm{V}^{\mathrm{V}}$ in the octahedral center. The presence of extra weak ligands in the octahedral $\mathrm{V}^{\mathrm{V}}$ center will facilitate their easy replacement by hydrogen peroxide and generate an active peroxo intermediate for the subsequent catalytic reaction of benzene hydroxylation. On the other hand, $\mathrm{NaY}-\mathrm{VO}_{x}$ samples (Figure 2a) show weak CT bands at 412 and $458 \mathrm{~nm}$ and strong CT band at 250 and $300 \mathrm{~nm}$ before and after heating. The results indicate that $\mathrm{NaY}-\mathrm{VO}_{x}$ samples exist mostly in tetrahedral $\mathrm{VO}_{x}$ and much less in octahedral $\mathrm{VO}_{x}$ which will reduce the amount of mobile ligands in the $\mathrm{V}^{\mathrm{V}}$ center needed for an effective catalytic activity which will be discussed later in the catalytic data.

Figure 3 shows the spectra of the samples obtained by direct encapsulation of $\mathrm{VO}(\mathrm{acac})_{2}$ in uncalcined samples of MCM41, MCM-48, and MAS-9. The above samples after calcinations in air, we obtained the UC-MCM-41-, UC-MCM-48-, and UCMAS-9- $\mathrm{VO}_{x}$ samples. The CT bands observed in the one-step calcinations, before heating (see parts $a-c$ of Figure 3 ) and those after heating (parts $a^{\prime}-c^{\prime}$ of Figure 3 ), show the same patterns as the multisteps process (cf. Figure 2). The catalytic data further demonstrate that the one-step process could provide a convenient 


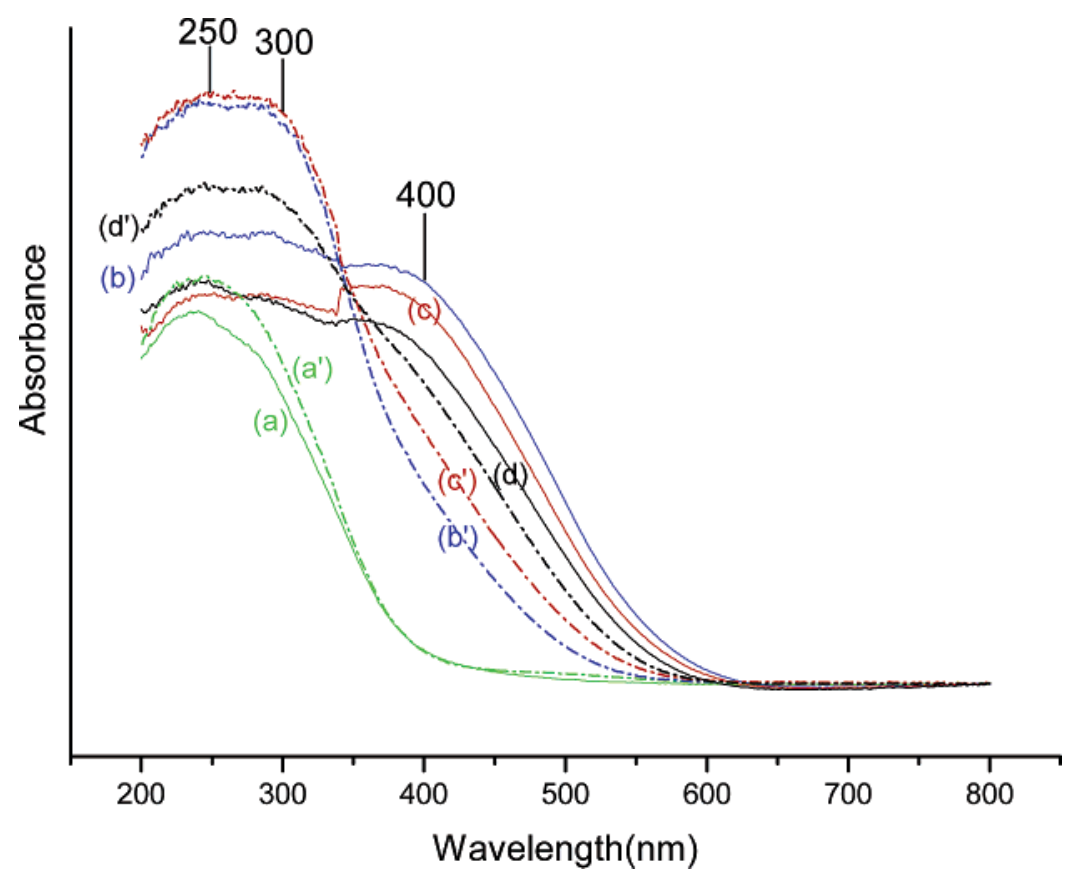

Figure 2. Diffuse reflectance UV-vis spectra of the following samples: (a) NaY- $\mathrm{VO}_{x}$, (b) MCM-41-VO $\mathrm{VO}_{x}$ samples before $(\mathrm{a}, \mathrm{b}$, and $\mathrm{c})$ and after $\left(\mathrm{a}^{\prime}, \mathrm{b}^{\prime}\right.$, and $\left.\mathrm{c}^{\prime}\right)$ heating at $300{ }^{\circ} \mathrm{C}$ for $2 \mathrm{~h}$.

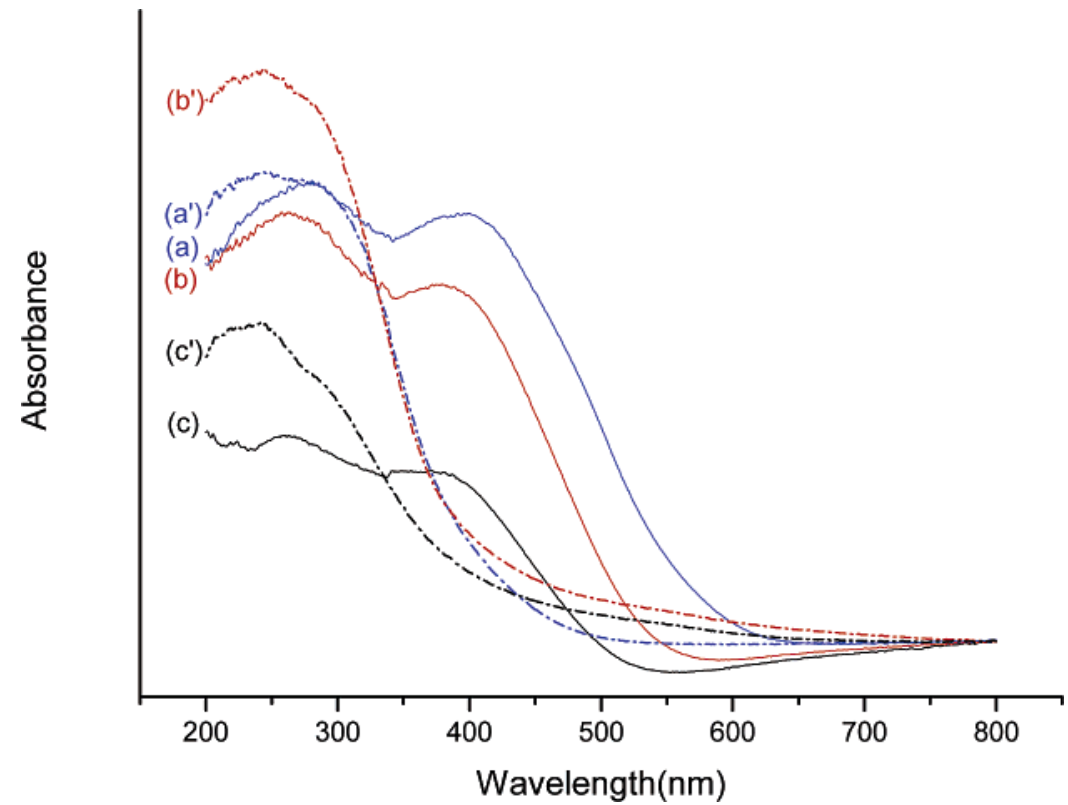

Figure 3. Diffuse reflectance UV-vis spectra of the following samples prepared by the one-step process: (a) UC-MCM-41-VO ${ }_{x}$, (b) UC-MCM48- $\mathrm{VO}_{x}$, and (c) UC-MAS-9-VO $\mathrm{VO}_{x}$ samples before (a, b, and c) and after $\left(\mathrm{a}^{\prime}, \mathrm{b}^{\prime}\right.$, and $\left.\mathrm{c}^{\prime}\right)$ heating at $300{ }^{\circ} \mathrm{C}$ for $2 \mathrm{~h}$.

and efficient method to prepare catalysts with high activity for the catalytic hydroxylation of benzene.

Figure 4 shows the $\mathrm{UV}$ - vis spectra of $\mathrm{V}^{\mathrm{V}}$ center supported on the following solids: (a) $\mathrm{Al}_{2} \mathrm{O}_{3}$, (b) $\mathrm{SiO}_{2}-\mathrm{N}_{1}$, (c) $\mathrm{SiO}_{2}-\mathrm{N}_{2}$, and (d) $\mathrm{SiO}_{2}-\mathrm{N}_{3}\left(\mathrm{~N}_{x}\right.$ refers to the number of amine group). The wavelength of the CT bands at 250 and $340 \mathrm{~nm}$ indicate that most of the $\mathrm{V}^{\mathrm{V}}$ centers are in the tetrahedral coordination on above supports (see Chart 2). The presence of amine groups in the organosilane may modify $\mathrm{SiO}_{2}$ and enhance coordination ability, but the amine groups may inhibit the coordination of hydrogen peroxide with the vanadium center and reduce the catalytic activity.

5. EPR Spectra. Figure 5 shows the EPR spectra of encapsulated $\mathrm{VO}(\mathrm{acac})_{2}$ complexes on different supports including NaY, MCM-41, MCM-48, and MAS-9 samples. All fresh MPS-VO(acac) 2 samples display similar EPR spectra (similar $g$ and hyperfine coupling $A$ values) at $80 \mathrm{~K}$. Upon raising the temperature, we observe a decrease in the spectral intensity, but no change in the spectral features (spectra not shown). The results indicate that the vanadyl complexes are well immobilized on solid supports. The spectra also display well-resolved hyperfine structure and no superimposed broad singlet, which indicates the $\mathrm{V}^{\mathrm{IV}}$ complexes appear to be isolated and highly dispersed. The $g$ and $A$ values of EPR spectra were typical of $\mathrm{V}^{\mathrm{IV}}$ species with a $\mathrm{d}^{1}$ configuration coupled to its own nuclear spin $\left({ }^{51} \mathrm{~V}, I=7 / 2\right.$, natural abundance $\left.99.8 \%\right)$, resulting in two axial symmetric sets of eight lines pattern. Previous EPR studies of $\mathrm{V}^{\mathrm{IV}}$ containing solids indicated different paramagnetic behaviors for $\mathrm{V}^{\mathrm{IV}}$ centers in the tetrahedral, square pyramidal, and distorted octahedral coordination. The $g$ and $A$ values depend on the crystal field splitting properties of ligands, such as electronegativity, ligand field strength, and the ability of 


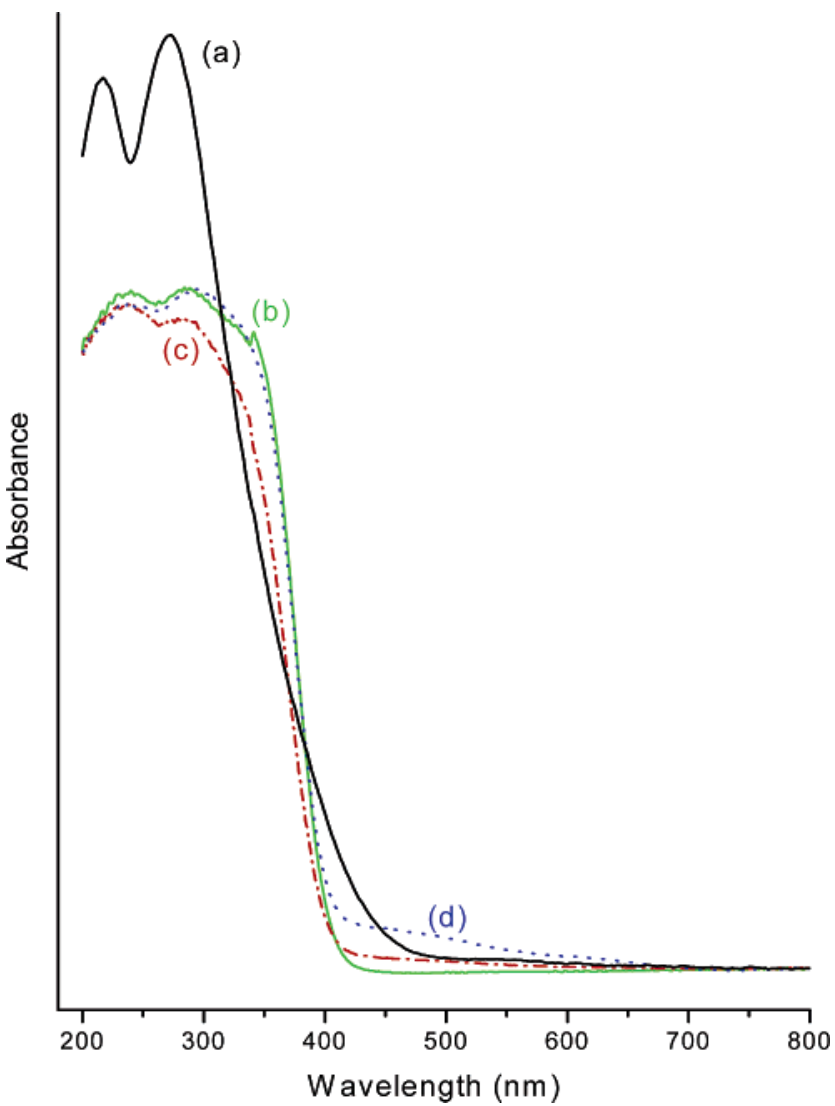

Figure 4. Diffuse reflectance UV-vis spectra of the following samples: (a) $\mathrm{Al}_{2} \mathrm{O}_{3}-\mathrm{VO}_{x}$, (b) $\mathrm{SiO}_{2}-\mathrm{N}_{1}-\mathrm{VO}_{x}$, (c) $\mathrm{SiO}_{2}-\mathrm{N}_{2}-\mathrm{VO}_{x}$, and (d) $\mathrm{SiO}_{2}-\mathrm{N}_{3}-\mathrm{VO}_{x}$, where $\mathrm{N}_{1}, \mathrm{~N}_{2}$, and $\mathrm{N}_{3}$ represent the number of amine groups per silane moiety.

CHART 2: Tetrahedral $\mathrm{V}^{\mathrm{V}}$ Symmetry in the Immobilization of $\mathrm{VO}_{3}{ }^{-}$in the Different Supports Including $\mathrm{Al}_{2} \mathrm{O}_{3}$ and Amine-Modified $\mathrm{SiO}_{2}$

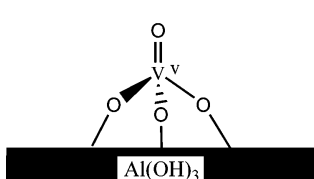

(A)

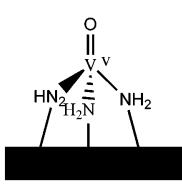

(B)

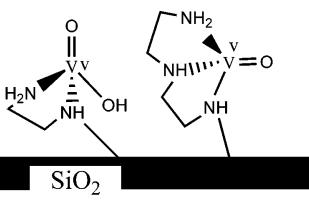

(C)

(D)
$\mathrm{SiO}_{2}-\mathrm{N}_{1}-\mathrm{VO}_{\mathrm{x}} \quad \mathrm{SiO}_{2}-\mathrm{N}_{2}-\mathrm{VO}_{\mathrm{x}} \quad \mathrm{SiO}_{2}-\mathrm{N}_{3}-\mathrm{VO}_{\mathrm{x}}$

$\pi$-bonding. In the tetrahedral site symmetry, the low-lying excitedstate will cause a very short spin-lattice relaxation time and the EPR spectra can only be observed below $77 \mathrm{~K}$. The spin Hamiltonian parameters of the distorted tetrahedral coordination in vanadium silicalite material were given as $g_{/ /}=1.912$ and $g_{\perp}$ $=1.963 .^{20}$ The square pyramidal and distorted octahedral coordination have a longer spin-lattice relaxation time, and the EPR spectra could be observed at room temperature. The $g_{/ /}$value of the $\mathrm{V}^{\mathrm{IV}}$ center is 1.945 in the square pyramidal coordination of vanadosilicate mesoporous MCM-41 and $\sim 1.931-1.941$ in the distorted octahedral coordination of different supports including $\mathrm{ZnSO}_{4} \cdot 7 \mathrm{H}_{2} \mathrm{O}, \mathrm{SiO}_{2}$, and vanadium silicate. ${ }^{19 \mathrm{a}-\mathrm{c}, 20,21}$

The fitted EPR parameters in Figure 5a are $g_{/ /}=1.935$ for $\mathrm{NaY}-\mathrm{VO}(\mathrm{acac})_{2}$ samples, and $g_{/ /}$are in the range of $1.942-$ 1.946 for MCM-41-, MCM-48-, and MAS-9-VO(acac) 2 samples. The $g$ values of $\mathrm{NaY}-\mathrm{VO}(\mathrm{acac})_{2}$ samples correspond to a distorted octahedral symmetry, and those of the MCM-41, MCM-48, and MAS-9-VO(acac $)_{2}$ samples belong to the square pyramidal coordination. Chart 1 represents the modes of vanadium coordination in the solid supports: square pyramidal (species A and B) and octahedral coordination (species $\mathrm{C}$ and

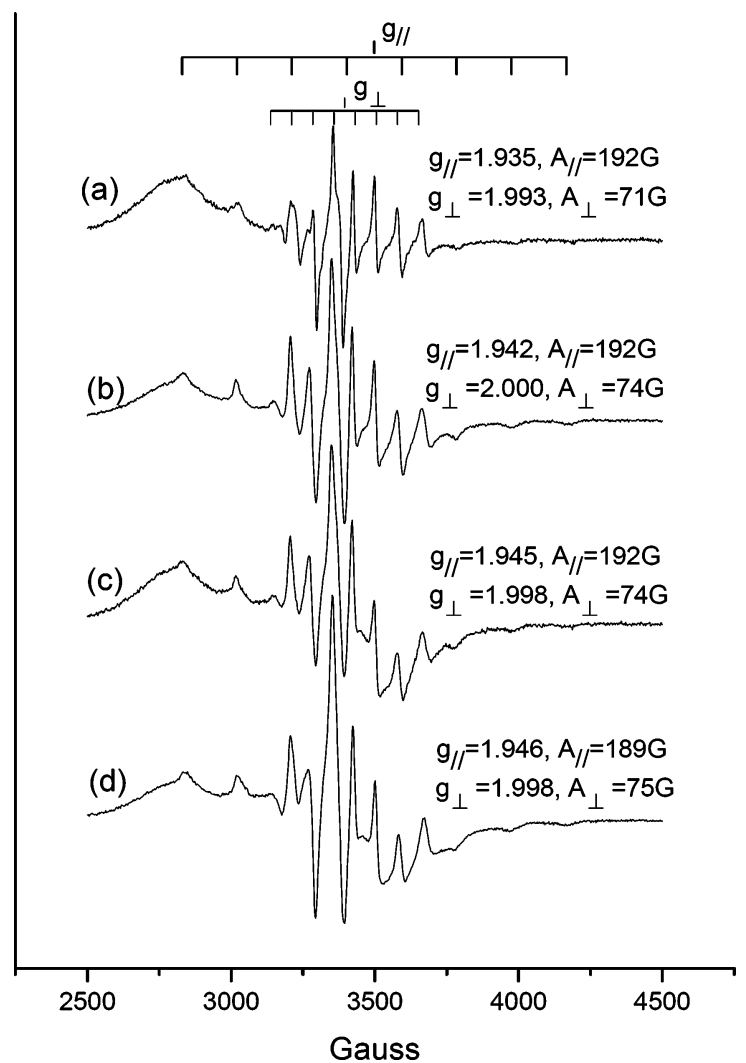

Figure 5. EPR spectra of the following $\mathrm{VO}(\mathrm{acac})_{2}$ containing samples at $80 \mathrm{~K}$ : (a) $\mathrm{NaY}-\mathrm{VO}(\mathrm{acac})_{2}$, (b) MCM-41-VO(acac) $)_{2}$, (c) MCM-48$\mathrm{VO}(\mathrm{acac})_{2}$, and (d) MAS-9- $\mathrm{VO}(\mathrm{acac})_{2}$.

D). The $\mathrm{VO}(\mathrm{acac})_{2}$ complexes could be anchored to the surface of inorganic supports by hydrogen bonding or a ligand-exchange mechanism. From the elemental analysis, we determine the NaY sample coordinated to about 0.5 acac ligand in every $\mathrm{V}^{\mathrm{IV}}$ center, and $\sim 1-2$ acac ligands in the MCM-41, MCM-48, and MAS-9 samples. From the results of EPR and elemental analysis, we may infer that the $\mathrm{NaY}$ sample exists in both $\mathrm{C}$ and $\mathrm{D}$ species, and MCM-41, MCM-48, and MAS-9 samples are in both A and $\mathrm{B}$ species (see Chart 1).

When the $\mathrm{VO}(\mathrm{acac})_{2}$ encapsulated samples were further calcinated in static air at $580{ }^{\circ} \mathrm{C}$, we observed that $\mathrm{V}^{\mathrm{IV}}$ species disappeared completely. The absence of the $\mathrm{V}^{\mathrm{IV}}$ signal in the EPR spectra indicates that the $\mathrm{V}^{\mathrm{IV}}$ centers are completely oxidized to $\mathrm{V}^{\mathrm{V}}$ by calcination. To further examine the nature of vanadium species in the calcined samples, the solids are reduced in a hydrogen atmosphere at $500{ }^{\circ} \mathrm{C}$ where we observe the hyperfine structure of $\mathrm{V}^{\mathrm{IV}}$ center. The paramagnetic parameters of the reduced samples show the $g_{/ /}$value in the range of 1.939-1.940 and $A_{/ /}$in the range of $197-199 \mathrm{G}$ (see Figure 6). The parameters in these ranges are typical of $\mathrm{V}^{\mathrm{IV}}$ in the distorted octahedral coordination that are strikingly different from those of $\mathrm{V}^{\mathrm{IV}}$ ions in the tetrahedral coordination.

Besides, we note a strong peak appears at $g=2.005$ in the spectra of reduced $\mathrm{NaY}-\mathrm{VO}_{x}$ sample (Figure 6a). We assign this strong peak to $\cdot \mathrm{O}_{2}{ }^{-}$adsorbed on the surface of reduced $\mathrm{NaY}-\mathrm{VO}_{x}$. It has been noted by Shvets and Kazanski that this adsorbed oxygen species is indicative the presence of $\mathrm{V}^{\mathrm{IV}}$ species in a tetrahedral environment, in the following manner ${ }^{22}$

$$
\left(\mathrm{V}^{\mathrm{IV}}\right)_{\text {tetra }}+\mathrm{O}_{2} \rightarrow \mathrm{V}^{\mathrm{V}}-\mathrm{O}_{2} \cdot-
$$

In our previous $\mathrm{UV}-$ vis studies of the $\mathrm{NaY}-\mathrm{VO}_{x}$ samples (Figure 2a), we observed the $\mathrm{V}^{\mathrm{V}}$ centers are mostly in a 


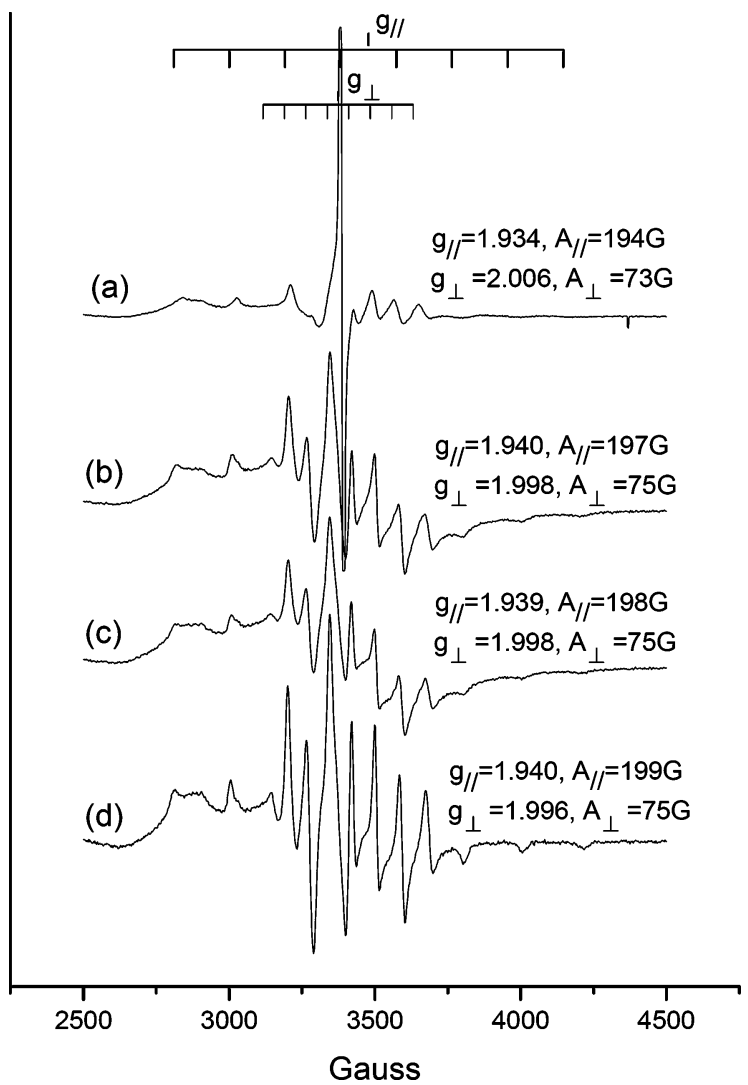

Figure 6. EPR spectra at $80 \mathrm{~K}$ of the following $\mathrm{VO}_{x}$ containing samples after reduction with hydrogen gas: (a) $\mathrm{NaY}-\mathrm{VO}_{x}$, (b) $\mathrm{MCM}-41-\mathrm{VO}_{x}$, (c) MCM-48-VO , and (d) MAS-9-VO ${ }_{x}$.

tetrahedral coordination and much less in octahedral. The same results can also be inferred from our EPR studies: we observe a weak distorted octahedral coordination with $g_{/ /}=1.934$ and $A_{/ /}=194 \mathrm{G}$ in the reduced $\mathrm{NaY}-\mathrm{VO}_{x}$ samples. The absence of tetrahedral $\mathrm{V}^{\mathrm{IV}}$ hyperfine signals in the EPR spectra may be attributed to a short spin-lattice relaxation time in the tetrahedral coordination where the EPR spectra can be observed only at very low temperatures.

Figure 7 shows the EPR spectra of encapsulated $\mathrm{VO}(\text { acac })_{2}$ complexes in the following uncalcined samples: (a) MCM-41, (b) MCM-48, and (c) MAS-9. In spectra a and b of Figure 7, we observe the $g_{/ /}$values are in the range of 1.942-1.943, which are very close to the $g_{/ /}$value of a square pyramidal or distorted octahedral coordination, so it is very difficult to distinguish between these two species. The same situation has also been reported in previous EPR studies. ${ }^{19-20}$ Furthermore, we observe a value $A_{\perp}=68 \mathrm{G}$ in the above two spectra, which is smaller than that of all the other $\mathrm{V}^{\mathrm{IV}}$ spectra either in the square pyramidal or distorted octahedral coordination $\left(A_{\perp}=74-75\right.$ $\mathrm{G})$. The decrease in the $A_{\perp}$ value may arise from the encapsulation of $\mathrm{VO}(\mathrm{acac})_{2}$ complexes in the nanochannels of uncalcined MCM-41 and MCM-48 samples for the following reasons. Once the $\mathrm{VO}(\mathrm{acac})_{2}$ complexes enter the uncalcined MCM-41 or MCM-48 samples, the electron-rich acac ligands in the VO$(\mathrm{acac})_{2}$ complexes could interact with the electron deficient ammonium group of the CTAB molecules. Consequently, we observed a small hyperfine splitting of the interacting ${ }^{14} \mathrm{~N}$ of the ammonium groups with the $\mathrm{V}^{\mathrm{IV}}$ center, which appear in the center of spectra a and $\mathrm{b}$ but not $\mathrm{c}$ of Figure 7 . The interaction of ${ }^{14} \mathrm{~N}$ with the $\mathrm{V}^{\mathrm{IV}}$ center will further lower the $A_{\perp}$ value in the above two spectra (spectra a and b of Figure 7). Interestingly, the paramagnetic parameters of spectra $a$ and $b$ of Figure 7 samples are almost the same as the as-synthesized V-MCM-41

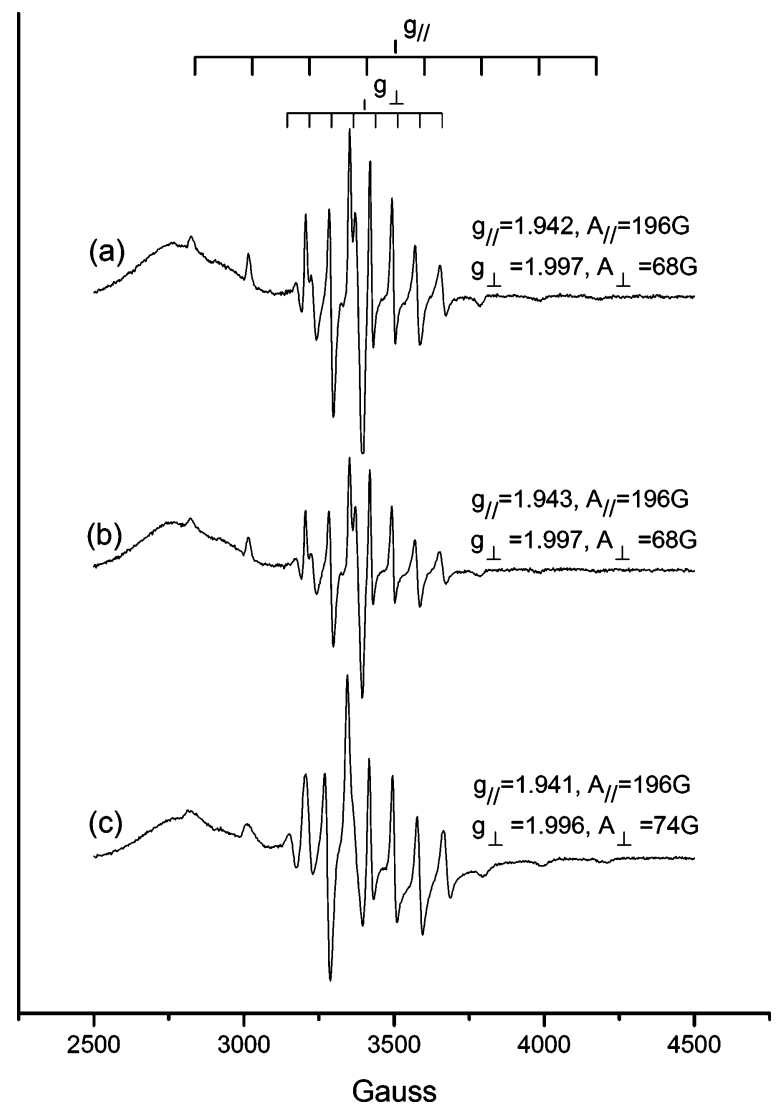

Figure 7. EPR spectra of the following samples at $80 \mathrm{~K}$ : (a) UCMCM-41-VO(acac $)_{2}$, (b) UC-MCM-48-VO(acac $)_{2}$, and (c) UC-MAS9- $\mathrm{VO}(\mathrm{acac})_{2}$.

with framework substituted where the remaining surfactant molecules (CTAB) in the nanochannels of MCM-41 can interact with the $\mathrm{V}^{\mathrm{IV}}$ center. Since we used a nonionic copolymer $\left(\mathrm{EO}_{20^{-}}\right.$ $\mathrm{PO}_{70} \mathrm{EO}_{20}$ ) as the template in the preparation of MAS-9 samples (Figure 7c), the interaction between the nonionic copolymer and acac ligands is weaker and results a value of $A_{\perp}=74 \mathrm{G}$ and a similar EPR line shape in comparison with Figure 5.

Figure 8 displays the EPR spectra of hydrogen-reduced UCMCM-41-, UC-MCM-48-, and UC-MAS-9-VO ${ }_{x}$ samples. After calcination and subsequent reduction, we observe the parameters of $g_{/ /}$are in the range of $1.937-1.939$ and $A_{/ /}$in the range of 199-203 G. These paramagnetic parameters indicate that the $\mathrm{V}^{\mathrm{IV}}$ species are in the distorted octahedral conformation and lack an interaction with the surrounding surfactant molecules. If we compare the spectra of the samples prepared by the onestep (spectra $a-c$ of Figure 8 ) and two-step (spectra $b-d$ of Figure 6 ) calcination, we find that their spin parameters are very similar $\left(A_{/ /} \approx 200 \mathrm{G}\right.$, and $\left.A_{\perp} \approx 75 \mathrm{G}\right)$. However, the small hyperfine splitting between the interacting ${ }^{14} \mathrm{~N}$ of the ammonium groups with $\mathrm{V}^{\mathrm{IV}}$ center disappears in UC-MCM-41- and UCMCM-48-VO(acac) $)_{2}$ samples after calcinations. The spectral changes indicate that the calcination removed the organic molecules, and the $\mathrm{V}^{\mathrm{IV}}$ center lost its interaction with the acac ligands and surfactant molecules. So the $\mathrm{V}^{\mathrm{IV}}$ center is most likely grafted on the surface of solid supports and achieved good stability. The results demonstrate that $\mathrm{VO}_{x}$ catalysts supported on MPS prepared by the one-step calcination is an effective method that $\mathrm{VO}(\mathrm{acac})_{2}$ complexes are first encapsulated in the uncalcined samples of MPS, then followed by calcinations.

From the above UV-vis and EPR spectral characterization, we observe that the catalytic center prepared by a one- and twostep calcination have very similar symmetry and environment. 


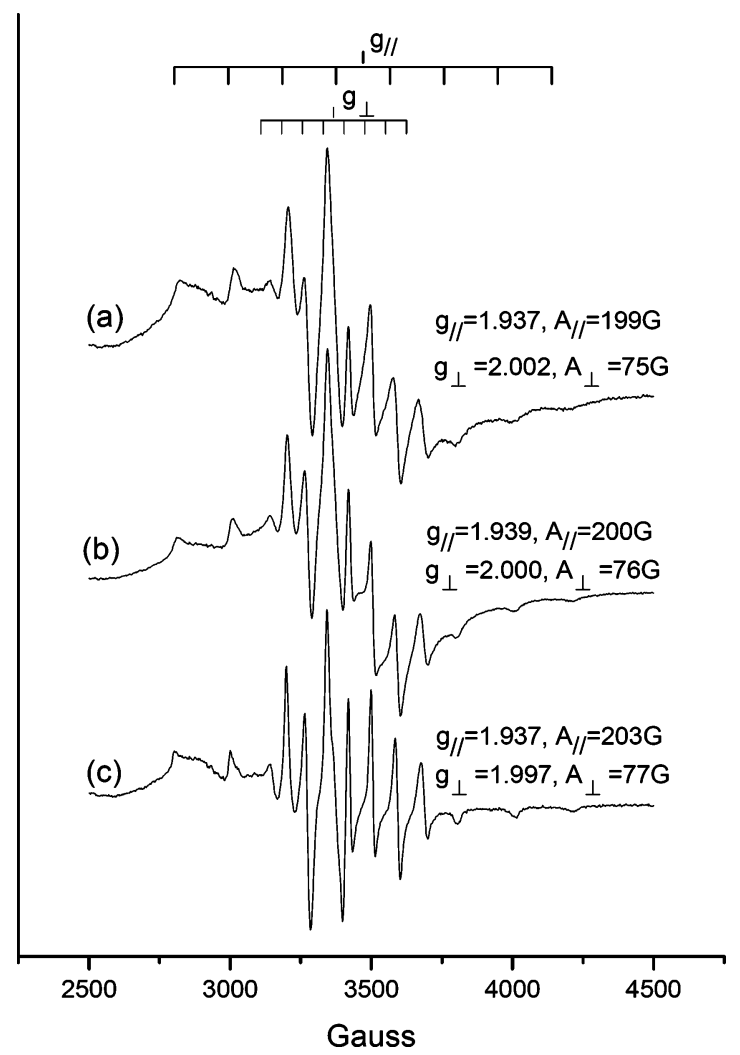

Figure 8. EPR spectra at $80 \mathrm{~K}$ of the following $\mathrm{VO}_{x}$ containing samples after reduction with hydrogen gas: (a) $\mathrm{UC}-\mathrm{MCM}-41-\mathrm{VO}_{x}$, (b) $\mathrm{UC}-$ MCM-48- $\mathrm{VO}_{x}$, and (c) UC-MAS-9- $\mathrm{VO}_{x}$.

TABLE 4: Turnover Numbers and Yields of Different Catalysts for the Hydroxylation of Benzene

\begin{tabular}{|c|c|c|c|c|}
\hline $\begin{array}{l}\text { hydroxylation } \\
\text { catalyst }\end{array}$ & $\begin{array}{c}\text { turnovers }^{a} \\
\left(\mathrm{~h}^{-1}\right)\end{array}$ & $\begin{array}{l}{ }^{a} \text { phenol } \\
(\mathrm{mmol})\end{array}$ & $\begin{array}{l}\text { 1,4-benzoquin } \\
\text { (mmol) }\end{array}$ & $\begin{array}{l}\text { e selectivity } \\
\text { of phenol }\end{array}$ \\
\hline $\mathrm{NaY}-\mathrm{VO}(\mathrm{acac})_{2}$ & 5.03 & 0.23 & 0.18 & 56 \\
\hline $\mathrm{MCM}-41-\mathrm{VO}(\mathrm{acac})_{2}$ & 4.06 & 0.21 & 0.12 & 64 \\
\hline $\mathrm{MCM}-48-\mathrm{VO}(\mathrm{acac})_{2}$ & 4.21 & 0.24 & 0.13 & 65 \\
\hline MAS-9-VO-(acac) $)_{2}$ & 3.63 & 0.21 & 0.13 & 62 \\
\hline $\mathrm{NaY}-\mathrm{VO}_{x}$ & $\sim 0$ & $\sim 0$ & 0.01 & 0 \\
\hline MCM-41-VO & 4.12 & 0.22 & 0.15 & 59 \\
\hline MCM-48- $\mathrm{VO}_{x}$ & 4.59 & 0.25 & 0.14 & 64 \\
\hline MAS-9-VO & 4.87 & 0.26 & 0.15 & 63 \\
\hline UC-MCM-41-VO ${ }_{x}$ & 6.31 & 0.17 & 0.09 & 65 \\
\hline UC-MCM-48-VO ${ }_{x}$ & 6.36 & 0.21 & 0.10 & 68 \\
\hline UC-MAS-9-VO ${ }_{x}$ & 7.08 & 0.28 & 0.06 & 82 \\
\hline $\mathrm{Al}_{2} \mathrm{O}_{3}-\mathrm{VO}_{x}$ & $\sim 0$ & $\sim 0$ & 0.01 & 0 \\
\hline $\mathrm{SiO}_{2}-\mathrm{N}_{1}-\mathrm{VO}_{x}$ & $\sim 0$ & $\sim 0$ & 0.02 & 0 \\
\hline $\mathrm{SiO}_{2}-\mathrm{N}_{2}-\mathrm{VO}_{x}$ & 1.44 & 0.10 & 0.05 & 67 \\
\hline $\mathrm{SiO}_{2}-\mathrm{N}_{3}-\mathrm{VO}_{x}$ & 2.03 & 0.12 & 0.09 & 57 \\
\hline
\end{tabular}

${ }^{a}$ The TON is the mol of benzene converted per mol of vanadium metal in $1 \mathrm{~h} .{ }^{\mathrm{b}}$ Selectivity calculated as $\mathrm{mol} \mathrm{phenol} /(\mathrm{mol} \mathrm{phenol}+\mathrm{mol}$ 1,4-benzoquinone). The reactions were carried out in $8.2 \mathrm{~mL}$ of acetonitrile as solvent using $10 \mathrm{mmol}$ benzene, $10 \mathrm{mmol} \mathrm{H}_{2} \mathrm{O}_{2}(35 \%)$, and $60 \mathrm{mg}$ of catalyst for $3 \mathrm{~h}$.

The catalytic data also show that both preparation methods give high catalytic activity. However, the one-step calcination yields a higher catalytic turnover number (see below). Thus, the onestep procedure is a fast and efficient method to prepare $\mathrm{VO}_{x}$ catalysts on MPS supports without losing their catalytic activity.

6. Catalytic Activities. We study the catalytic hydroxylation of benzene by $\mathrm{VO}(\mathrm{acac})_{2}$ complexes and $\mathrm{VO}_{x}$ species supported on Al-MPS samples. The results of the oxidation of benzene are summarized in Table 4. Our EPR studies show that the $\mathrm{V}^{\mathrm{IV}}$ center in $\mathrm{NaY}-\mathrm{VO}(\mathrm{acac})_{2}$ is in the distorted octahedral (Chart 1, species C or D) and MCM-41-, MCM-48-, and MAS-9-VO- (acac) 2 samples are in the square pyramidal coordination (Chart 1 , species $\mathrm{A}$ and $\mathrm{B})$. We note that the activity $(\mathrm{TON}=5.03$ $\mathrm{h}^{-1}$ ) of $\mathrm{NaY}-\mathrm{VO}(\mathrm{acac})_{2}$ samples are higher than those of MCM-41-, MCM-48-, and MAS-9-VO(acac) 2 samples (TONs were $4.06,4.21$, and $3.63 \mathrm{~h}^{-1}$, respectively). The high activity of the $\mathrm{NaY}-\mathrm{VO}(\mathrm{acac})_{2}$ catalyst is attributed to the presence of species $\mathrm{C}$ and $\mathrm{D}$ that contain more mobile ligands (denoted as $\mathrm{S})$ : 2 in species $\mathrm{C}$ and 3 in species $\mathrm{D}$ in the $\mathrm{V}^{\mathrm{IV}}$ center and therefore cause an easy replacement by hydrogen peroxide to generate the active peroxo radical intermediates.

We next examine the catalytic activities of calcined MPS$\mathrm{VO}_{x}$ samples which are listed in Table 4. We note that the $\mathrm{NaY}-\mathrm{VO}(\mathrm{acac})_{2}$ sample after calcinations lost its catalytic activity (turnover number dropped to near $0 \mathrm{~h}^{-1}$ ). However, we observe a slight increase in the turnover number of MCM-41, MCM-48, and MAS-9 samples: 4.12, 4.59, and 4.87, respectively. The loss of catalytic activity in $\mathrm{NaY}-\mathrm{VO}_{x}$ samples is attributed to the transformation of the distorted octahedral $\mathrm{V}^{\mathrm{IV}}$ to the tetrahedral $\mathrm{V}^{\mathrm{V}}$ during the calcination. These results are also consistent with the results of previous UV-vis and EPR studies of $\mathrm{NaY}-\mathrm{VO}_{x}$ samples where the vanadium center was identified in a tetrahedral coordination (Figures $2 \mathrm{a}$ and $6 \mathrm{a}$ ). Since $\mathrm{NaY}-\mathrm{VO}_{x}$ samples lack a mobile group in the tetrahedral $\mathrm{V}^{\mathrm{V}}$ center, it could yield fewer amounts of active intermediates to meet the catalytic prerequisite.

On the other hand, the slight increase in the catalytic activity

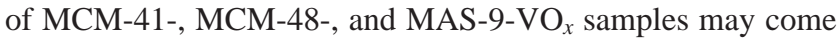
from the transformation of the square pyramidal (Chart 1, species A or B) to distorted octahedral species (Scheme 1, species B) which is consistent with the appearance of the CT band at $450 \mathrm{~nm}$ and a set of $g_{/ /}$near 1.934 in the reduced samples. The presence of $\mathrm{V}^{\mathrm{V}}$ centers in a distorted octahedral coordination provide more mobile ligands than that in the square pyramidal which can promote the formation of active intermediates and increase the catalytic activity. Furthermore, the turnover numbers of the UC-MCM-41-, UC-MCM-48-, and UC-MAS9- $\mathrm{VO}_{x}$ samples are in the range of $6-7 \mathrm{~h}^{-1}$ which are higher than those of MCM-41-, MCM-48-, and MAS-9-VO ${ }_{x}$ samples. The results show that we can achieve the high activity of $\mathrm{VO}_{x}$ catalysts supported on MPS solids prepared by a one-step procedure: encapsulate $\mathrm{VO}(\mathrm{acac})_{2}$ complexes directly in the nanochannels of uncalcined samples of MPS, then followed by calcinations in the ambient air atmosphere. We further note that catalytic activity of UC-MAS-9- $\mathrm{VO}_{x}$ samples is higher than those of UC-MCM-41- and UC-MCM-48-VO ${ }_{x}$ samples. We attribute this effect to the large pore size of MAS-9 supports, i.e., the substrates and products could easily pass in and out of the nanochannels and enhance the catalytic activity.

For comparison purposes, we further examine the catalytic activity of vanadium centers in different symmetry by encapsulating $\mathrm{NH}_{4} \mathrm{VO}_{3}$ on different solid supports including $\mathrm{Al}_{2} \mathrm{O}_{3}$ and mono-, di-, triamine-modified $\mathrm{SiO}_{2}$. Tetrahedral $\mathrm{V}^{\mathrm{V}}$ catalytic centers could be prepared either by the impregnation of $\mathrm{NH}_{4-}^{-}$ $\mathrm{VO}_{3}$ on $\mathrm{Al}_{2} \mathrm{O}_{3}$ or coordination of $\mathrm{V}^{\mathrm{V}}$ centers with mono-, di-, or triamine-modified $\mathrm{SiO}_{2}$. Chart 2 shows the presence of possible tetrahedral symmetry in $\mathrm{Al}_{2} \mathrm{O}_{3}$ and amine-modified $\mathrm{SiO}_{2}$. The $\mathrm{V}^{\mathrm{V}}$ centers on these supported surface lack mobile ligands (S) which are the essential elements to carry out the catalytic reaction, thus we observe low TON, about from 0 to $2 \mathrm{~h}^{-1}$ in the this group of supports.

The catalytic reaction was monitored by HPLC. The main products for the hydroxylation of benzene are phenol and 1,4benzoquinone. The mole ratio of these two products, phenol and 1,4-benzoquinone, in the benzene hydroxylation is about two. The highest phenol yields were 0.26 and $0.28 \mathrm{mmol}$ in 
SCHEME 1: Catalytic Mechanism of the Hydroxylation of Benzene by VO(acac $)_{2}$ and $\mathrm{VO}_{x}$ Encapsulated in the Nanochannels of MPS Solids

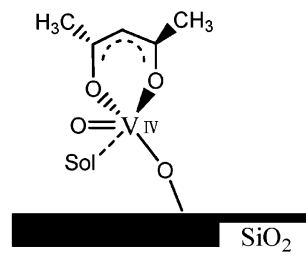

(A)

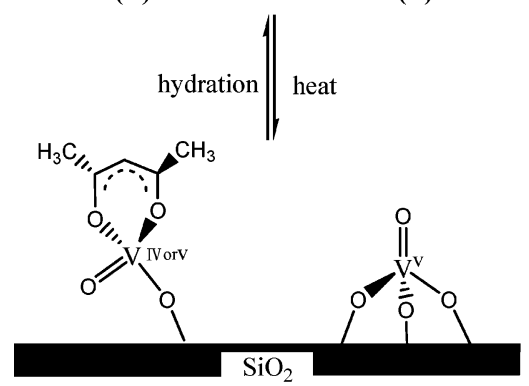

(G)
(H)

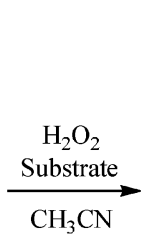

$\underset{\mathrm{CH}_{3} \mathrm{CN}}{\longrightarrow}$

(n)
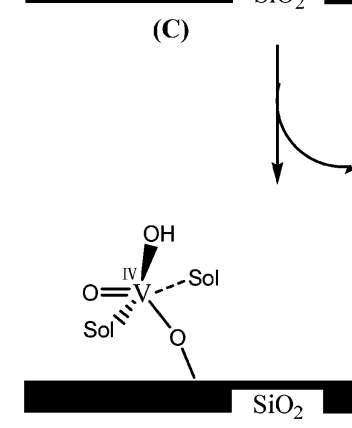

(E)

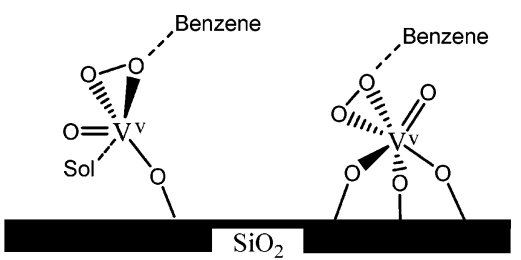

(D)

MAS-9-VO VO $_{x}$ UC-MAS-9-VO ${ }_{x}$ samples, respectively. 1,4Benzoquinone is a byproduct that was formed in the catalytic process due to the fact that phenols (a polar molecule) have a higher re-entry rate into the hydrophilic channels of MPS than the nonpolar benzene. ${ }^{23}$ Besides, phenol molecules are electron rich and have higher activity than benzene. Once phenols enter the channels of MPS, they can undergo further oxidation or hydroxylation. We are striving to improve the characteristics of the supports and the types of catalytic center so that we may enhance both the selectivity and reactivity.

7. Catalytic Mechanism. On the basis of the above spectroscopic studies, we propose a mechanism for the catalytic oxidation of benzene, as illustrated in Scheme 1. From UVvis and EPR studies of MPS- VO(acac $)_{2}$ and $\mathrm{MPS}-\mathrm{VO}_{x}$ samples, we assign the vanadium centers in MPS- $\mathrm{VO}(\text { acac })_{2}$ samples to a square pyramidal (species A) and that in MCM41- $\mathrm{VO}_{x}$ samples to a distorted octahedral symmetry (species B). We note that both species A and B have one or two mobile ligands (denoted as Sol in Scheme 1). However, the vanadium centers of species A and B could convert to species $\mathrm{G}$ and $\mathrm{H}$ after heating that placed the catalytic center in a tetrahedral coordination. By the addition of hydrogen peroxide, the mobile ligands of species A and B will be replaced and an intermediate like inorganic peracid (not shown) or peroxo (species C and D) type will be formed. ${ }^{4 a, 24}$ The peroxo radicals could be derived from the above two intermediates, and the substrate (benzene) could interact with the active intermediates to generate phenols via radical intermediates.

\section{Conclusions}

In this study, we have demonstrated monodispersion of $\mathrm{VO}_{x}$ catalyst supported on a high surface area of Al-MPS could be prepared by MDD method using $\mathrm{VO}(\mathrm{acac})_{2}$ as a precursor. We found that $\mathrm{VO}(\mathrm{acac})_{2}$ could form as mobile ligands with the active silanol groups of MPS surface and facilitate the formation of active $\mathrm{VO}_{x}$ centers after calcination. Furthermore, the site isolation of the catalytic centers in solid supports could enhance the catalytic activity of the hydroxylation of benzene. From the analysis of the catalytic activity, we found that good mobile ligands (i.e., solvent or $\mathrm{H}_{2} \mathrm{O}$ ) in the octahedral coordination of $\mathrm{V}^{\mathrm{V}}$ center is a key factor to achieve high reactivity. The good leaving groups in the octahedral vanadium centers promote the addition of hydrogen peroxide to the vanadium centers and

subsequently form active peroxo intermediates to facilitate the hydroxylation of benzene. On the other hand, the strong coordination (amine ligands) in the tetrahedral $\mathrm{V}^{\mathrm{V}}$ center lacking mobile ligands will lower the catalytic activities. We further demonstrate that the one-step calcination process is a very convenient and effective method to prepare the highly reactive $\mathrm{V}^{\mathrm{V}}$ centers in comparison with the conventional multisteps process. As noted in Table 4, the groups of UC-MPS materials prepared by the one-step process have higher TONs and comparable phenol yields than others.

Acknowledgment. The work was supported partially by a grant to C.-Y.M. from NSC (NSC-94-2752-M -002-004-PAE) and a pilot project grant from the AFOSR Nanoscience Initiative Program.

\section{References and Notes}

(1) Weissermel, K.; Arpe, H. J. Industrial Organic Chemistry, 3rd ed.; VCH publishers: New York, 1997.

(2) (a) Sheldon, R. A.; Kochi, J. K. Metal-Catalyzed Oxidations of Organic Compounds; Academic Press: New York, 1981. (b) Centi, G.; Cavani, F.; Trifiro, F. Selective Oxidation by Heterogeneous Catalysis; Academic Press: New York, 2001.

(3) (a) Niwa, S.; Eswaramoorthy, M.; Nair, J.; Raj, A.; Itoh, N.; Shoji, H.; Namba, T.; Mizukami, F. Science 2002, 295, 105-107. (b) Vulpescu, G. D.; Ruitenbeek, M.; Van Lieshout, L. L.; Correia, L. A.; Meyer, D.; Pex, P. P. A. C. Catal. Commun. 2004, 5, 347-351.

(4) (a) Alekar, N. A.; Indira, V.; Halligudi, S. B.; Srinivas, D.; Gopinathan, S.; Gopinathan, C. J. Mol. Catal. A 2000, 164, 181-189. (b) Nomiya, K.; Matsuoka, S.; Hasegawa, T.; Nemoto, Y. J. Mol. Catal. A 2000, 156, 143-152. (c) Thangaraj, A.; Kumar, R.; Ratnasamy, P. Appl. Catal. 1990, 57, L1-L3. (d) Zhang, J.; Tang, Y.; Li, G. Y.; Hu, C. Appl. Catal. A 2005, 278, 251-261. (e) Nomiya, K.; Yanagibayashi, H.; Nozaki, C.; Kondoh, K.; Hiramatsu, E.; Shimizu, Y. J. Mol. Catal. A 1996, 114, 181-190. (f) Kuznetsova, L. I.; Detusheva, L. G.; Fedotov, M. A.; Likholobov, V. A. J. Mol. Catal. A 1996, 111, 81-90. (g) Bengoa, J. F.; Gallegos, N. G.; Marchetti, S. G.; Alvarez, A. M.; Cagnoli, M. V.; Yeramian, A. A. Microporous Mesoporous Mat. 1998, 24, 163-172. (h) Kanzaki, H.; Kitamura, T.; Hamada, R.; Nishiyama, S.; Tsuruya, S. J. Mol. Catal. A 2004, 208, 203-211. (i) Balducci, L.; Bianchi, D.; Bortolo, R.; D’Aloisio, R.; Ricci, M.; Tassinari, R.; Ungarelli, R. Angew. Chem., Int. Ed. 2003, 42, 4937-4940. (j) Miyahara, T.; Kanzaki, H.; Hamada, R.; Kuroiwa, S.; Nishiyama, S.; Tsuruya, S. J. Mol. Catal. A 2001, 176, 141-150. (k) Stockmann, M.; Konietzni, F.; Notheis, J. U.; Voss, J.; Keune, W.; Maier, W. F. Appl. Catal. A 2001, 208, 343-358. (1) Kim, G. J.; Cho, B. R.; Kim, J. H. Catal. Lett. 1993, 22, 259-270. (m) Tanev, P. T.; Chibwe, M.; Pinnavaia, T. J. Nature 1994, 368, 321-323. (n) Tang, Y.; Zhang, J. Trans. Metal. Chem. 2006, 31, 299-305. (o) Waclaw, A.; Nowinska, K.; Schwieger, W. Appl. Catal. A 2004, 270, 151-156. (p) Jian, M.; Zhu, L. F.; Wang, J. Y.; Zhang, J.; Li, G. Y.; Hu, C. W. J. Mol. Catal. A 2006, 
253, 1-7. (q) Nomiya, K.; Yagishita, K.; Nemoto, Y.; Kamataki, T. A. J. Mol. Catal. A 1997, 126, 43-53. (r) Kumar, R.; Mukherjee, P.; Bhaumik, A. Catal. Today 1999, 49, 185-191. (s) Raja, R.; Ratnasamy, P. Stud. Surf. Sci. Catal. 1997, 105, 1037-1044. (t) Arends, I. W. C. E.; Sheldon, R. A Appl. Catal. A 2001, 212, 175-187.

(5) (a) Remias, J. E.; Pavlosky, T. A.; Sen, A. J. Mol. Catal. A 2003, 203, 179-192. (b) Panov, G. I.; Sheveleva, G. A.; Kharitonov, A. S.; Romannikov, V. N.; Vostrikova, L. A. Appl. Catal. A 1992, 82, 31-36. (c) Hafele, M.; Reitzmann, A.; Roppelt, D.; Emig, G. Appl. Catal. A 1997 150, 153-164. (d) Passoni, L. C.; Cruz, A. T.; Buffon, R.; Schuchardt, U. J. Mol. Catal. A 1997, 120, 117-123. (e) Burch, R.; Howitt, C. Appl. Catal. A 1993, 103, 135-162. (f) Yuranov, I.; Bulushev, D. A.; Renken, A.; KiwiMinsker, L. J. Catal. 2004, 227, 138-147. (g) Yoo, J. S.; Sohail, A. R.; Grimmer, S. S., Shyu, J. Z. Appl. Catal. A 1994, 117, 1-16. (h) Bal, R. Tada, M.; Sasaki, T.; Iwasawa, Y. Angew. Chem., Int. Ed. 2006, 45, 448452. (i) Taboada, J. B.; Hensen, E. J. M.; Arends, I. W. C. E.; Mul, G.; Overweg, A. R. Catal. Today 2005, 110, 221-227. (j) Castagnola, N. B.; Kropf, A. J.; Marshall, C. L. Appl. Catal. A 2005, 290, 110-122. (k) Pillai, K. S.; Jia, J. F.; Sachtler, W. M. H. Appl. Catal. A 2004, 264, 133-139. (1) Zhu, Q.; van Teeffelen, R. M.; van Santen, R. A.; Hensen, E. J. M. J. Catal. 2004, 221, 575-583. (m) Seo, Y. J.; Mukai, Y.; Tagawa, T.; Goto, S. J. Mol. Catal. A 1997, 120, 149-154. (n) Miyake, T.; Hamada, M., Sasaki, Y.; Oguri, M. Appl. Catal. A 1995, 131, 33-42. (o) Laufer, W.; Hoelderich, W. F. Chem. Commun. 2002, 1684-1685.

(6) Vassileva, M.; Andreev, A.; Dancheva, S.; Kotsev, N. Appl. Catal. 1989, 49, 125-141

(7) (a) Ferreira, R. S. G.; de Oliveira, P. G. P.; Noronha, F. B. Appl. Catal. B 2001, 29, 275-283. (b) Ferreira, R. S. G.; de Oliveira, P. G. P.; Noronha, F. B. Appl. Catal. B 2004, 50, 243-249.

(8) Lemke, K.; Ehrich, H.; Lohse, U.; Berndt, H.; Jahnisch, K. Appl. Catal. A 2003, 243, 41-51.

(9) Christodoulakis, A.; Machli, M.; Lemonidou, A. A.; Boghosian, S. J. Catal. 2004, 222, 293-306.

(10) (a) Parvulescu, V.; Anastasescu, C.; Su, B. L. J. Mol. Catal. A 2004, 211, 143-148. (b) Parvulescu, V.; Anastasescu, C.; Su, B. L. J. Mol. Catal. A 2003, 198, 249-261.

(11) Kwak, J. H.; Herrera, J. E.; Hu, J. Z.; Wang, Y.; Peden, C. H. F. Appl. Catal. A 2006, 300, 109-119.

(12) Ringenbach, C. R.; Livingston, S. R.; Kumar, D.; Landry, C. C. Chem. Mater. 2005, 17, 5580-5586.

(13) (a) Shylesh, S.; Singh, A. P. J. Catal. 2005, 233, 359-371. (b) George, J.; Shylesh, S.; Singh, A. P. Appl. Catal. A 2005, 290, 148-158. (c) Shylesh, S.; Mirajkar, S. P.; Singh, A. P. J. Mol. Catal. A 2005, 239 57-63. (d) Dimitrova, R.; Spassova, M.; Kostova, N.; Tsoncheva, T.; Ivanova, L.; Minchev, C. Appl. Catal. A 2006, 303, 207-212. (e) Shiraishi, Y.; Morishita, M.; Teshima, Y.; Hirai, T. J. Phys. Chem. B 2006, 110, 6587-6594. (f) Du, G. A.; Lim, S. Y.; Yang, Y. H.; Wang, C.; Pfefferle, L.; Haller, G. L. Appl. Catal. A 2006, 302, 48-61. (g) Shetti, V. N.; Rani, M. J.; Srinivas, D.; Ratnasamy, P. J. Phys. Chem. B 2006, 110, 677-679. (h) Moussa, N.; Fraile, J. M.; Ghorbel, A.; Mayoral, J. A. J. Mol. Catal. A 2006, 255, 62-68. (i) Zhang, W. Z.; Wang, J. L.; Tanev, P. T.; Pinnavaia, T. J. Chem. Commun. 1996, 21, 979-980. (j) Dapurkar, S. E.; Sakthivel, A.; Selvam, P. J. Mol. Catal. A 2004, 223, 241-250. (k) Jia, M. J.; Valenzuela, R. X.; Amoros, P.; Beltran-Porter, D.; El-Haskouri, J.; Marcos, M. D.; Corberan, V. C. Catal. Today 2004, 15, 43-47. (1) Farzaneh, F.; Zamanifar, E.; Williams, C. D. J. Mol. Catal. A 2004, 218, 203-209. (m) Kilos, B.; Aouine, M.; Nowak, I.; Ziolek, M.; Volta, J. C. J. Catal. 2004 224, 314-325. (n) Yoshitake, H.; Tatsumi, T. Chem. Mater. 2003, 15, 1695-1702. (o) Dzwigaj, S.; Krafft, J. M.; Che, M.; Lim, S.; Haller, G. L. J. Phys. Chem. B 2003, 107, 3856-3861. (p) Lim, S.; Haller, G. L. J. Phys. Chem. B 2002, 106, 8437-8448. (q) Laha, S. C.; Kumar, R. Microporous Mesoporous Mat. 2002, 53, 163-177. (r) Reddy, E. P.; Davydov, L.; Smirniotis, P. G. J. Phys. Chem. B 2002, 106, 3394-3401. (s) Trukhan, N. N.; Romannikov, V. N.; Paukshtis, E. A.; Shmakov, A. N.; Kholdeeva, O. A. J. Catal. 2001, 202, 110-117. (t) Trukhan, N. N.; Derevyankin, A. Y.; Shmakov, A. N.; Paukshtis, E. A.; Kholdeeva, O. A.; Romannikov, V. N. Microporous Mesoporous Mat. 2001, 44, 603-608. (u) Luan, Z. H.; Bae, J. Y.; Kevan, L. Chem. Mater. 2000, 12, 3202-3207. (v) Arnold, A. B. J.;
Niederer, J. P. M.; Niessen, T. E. W.; Holderich, W. F. Microporous Mesoporous Mat. 1999, 28, 353-360. (w) Wei, D.; Wang, H.; Feng, X. B.; Chueh, W. T.; Ravikovitch, P.; Lyubovsky, M.; Li, C.; Takeguchi, T.; Haller, G. L. J. Phys. Chem. B 1999, 103, 2113-2121.

(14) (a) Choi, J. S.; Kim, T. H.; Choo, K. Y.; Sung, J. S.; Saidutta, M B.; Ryu, S. O.; Song, S. D.; Ramachandra, B.; Rhee, Y. W. Appl. Catal. A 2005, 290, 1-8. (b) Liu, Y. M.; Feng, W. L.; Li, T. C.; He, H. Y.; Dai, W. L.; Huang, W.; Cao, Y.; Fan, K. N. J. Catal. 2006, 239, 125-136. (c) Nguyen, L. D.; Loridant, S.; Launay, H.; Pigamo, A.; Dubois, J. L.; Millet, J. M. M. J. Catal. 2006, 237, 38-48. (d) Concepcion, P.; Navarro, M. T.; Blasco, T.; Nieto, J. M. L.; Panzacchi, B.; Rey, F. Catal. Today 2004, 96, 179-186. (e) Liu, Y. M.; Cao, Y.; Yi, N.; Feng, W. L.; Dai, W. L.; Yan, S. R.; He, H. Y.; Fan, K. N. J. Catal. 2004, 224, 417-428. (f) Fornes, V.; Lopez, C.; Lopez, H. H.; Martinez, A. Appl. Catal. A 2003, 249, 345-354. (g) Liu, Y. M.; Cao, Y.; Zhu, K. K.; Yan, S. R.; Dai, W. L.; He, H. Y.; Fan, K. N. Chem. Commun. 2002, 2832-2833. (h) Lang, N.; Delichere, P.; Tuel, A. Microporous Mesoporous Mat. 2002, 56, 203-217. (i) Berndt, H.; Martin, A.; Bruckner, A.; Schreier, E.; Muller, D.; Kosslick, H.; Wolf, G. U.; Lucke, B. J. Catal. 2000, 191, 384-400.

(15) (a) Shylesh, S.; Singh, A. P. J. Catal. 2004, 228, 333-346. (b) Dimitrova, R.; Spassova, M.; Kostova, N.; Tsoncheva, T.; Ivanova, L.; Minchev, C. Appl. Catal. A 2006, 303, 207-212. (c) Kwak, J. H.; Herrera, J. E.; Hu, J. Z.; Wang, Y.; Peden, C. H. F. Appl. Catal. A 2006, 300, 109119. (d) Hess, C.; Drake, I. J.; Hoefelmeyer, J. D.; Tilley, T. D.; Bell, A. T. Catal. Lett. 2005, 105, 1-8. (e) Fujishima, K.; Fukuoka, A.; Yamagishi, A.; Inagaki, S.; Fukushima, Y.; Ichikawa, M. J. Mol. Catal. A 2001, 166 211-218. (f) Pena, M. L.; Dejoz, A.; Fornes, V.; Rey, E.; Vazquez, M. I.; Nieto, J. M. L. Appl. Catal. A 2001, 209, 155-164.

(16) Lee, C. H.; Lin, T. S.; Mou, C. Y. J. Phys Chem. B 2003, 107, 2543-2551.

(17) (a) Baltes, M.; Cassiers, K.; Van, Der, Voort, P.; Weckhuysen, B. M.; Schoonheydt, R. A.; Vansant, E. F. J. Catal. 2001, 197, 160-171. (b) Baltes, M.; Van Der Voort, P.; Weckhuysen, B. M.; Rao, R. R.; Catana, G.; Schoonheydt, R. A.; Vansant, E. F. Phys. Chem. Chem. Phys. 2000, 2, 2673-2680. (c) Van Der Voort, P.; White, M. G.; Vansant, E. F. Langmuir 1998, 14, 106-112. (d) Baltes, M.; Collart, O.; Van Der Voort, P.; Vansant, E. F. Langmuir 1999, 15, 5841-5845. (e) Van Der Voort, P.; Baltes, M.; Vansant, E. F. J. Phys. Chem. B 1999, 103, 10102-10108. (f) Kustrowski, P.; Chmielarz, L.; Dziembaj, R.; Cool, P.; Vansant, E. F. J. Phys. Chem. B 2005, 109, 11552-11558. (g). Prinetto, F.; Ghiotti, G.; Occhiuzzi, M.; Indovina, V. J. Phys. Chem. B 1998, 102, 10316-10325. (h) Van, Der, Voort, P.; Babitch, I. V.; Grobet, P. J.; Verberckmoes, A. A.; Vansant, E. F. J. Chem. Soc. Faraday Trans. 1996, 92, 3635-3642. (i) Van Der Voort, P.; Possemiers, K.; Vansant, E. F. J. Chem. Soc. Faraday Trans. 1996, 92, 843-848. (j) Segura, Y.; Cool, P.; Van Der Voort, P.; Mees, F.; Meynen, V.; Vansant, E. F. J. Phys. Chem. B 2004, 108, 3794-3800.

(18) (a) Lee, C. H.; Lang, J.; Yen, C. W.; Shih, P. C.; Lin, T. S.; Mou, C. Y. J. Phys. Chem. B 2005, 109, 12277-12286. (b) Han, Y.; Wu, S.; Sun, Y.; Li, D.; Xiao, F. S.; Liu, J.; Zhang, X. Chem. Mater. 2002, 14, 1144.

(19) (a) Luan, Z. H.; Xu, J.; He, H. Y.; Klinowski, J.; Kevan, L. J. Phys. Chem. 1996, 100, 19595-19602. (b) Luan, Z. H.; Kevan, L. J. Phys. Chem. B 1997, 101, 2020-2027. (c) Luan, Z. H.; Zhao, D. Y.; Kevan, L. Microporous Mesoporous Mat. 1998, 20, 93-99. (d) Zhang, Q. H.; Wang, Y.; Ohishi, Y.; Shishido, T.; Takehira, K. J. Catal. 2001, 202, 308-318. (e) Selvam, P.; Dapurkar, S. E. J. Catal. 2005, 229, 64-71. (f) Dai, L. X.; Tabata, K.; Suzuki, E.; Tatsumi, T. Chem. Mater. 2001, 13, 208-212. (g) Lee, C. W.; Lee, W. J.; Park, Y. K.; Park, S. E. Catal. Today 2000, 61, $137-141$.

(20) Prakash, A. M.; Kevan, L. J. Phys. Chem. B 2000, 104, 68606868

(21) Chatterjee, M.; Iwasaki, T.; Hayashi, H.; Onodera, Y.; Ebina, T.; Nagase, T. Chem. Mater. 1999, 11, 1368-1375.

(22) Centi, G.; Perathoner, S.; Trifiro, F.; Aboukais, A.; Aissi, C. F.; Guelton, M. J. Phys. Chem. 1992, 96, 2617-2629.

(23) Goor, G. Catalytic Oxidations with Hydrogen Peroxide as Oxidant; Kluwer Academic Publishers: Dordrecht, 1992.

(24) Neumann, R.; Levin-Elad, M. Appl. Catal. A 1995, 122, 85-97. 